\title{
Expression of Ion Channels and Mutational Effects in Giant Drosophila Neurons Differentiated from Cell Division-arrested Embryonic Neuroblasts
}

\author{
Mitsuyoshi Saito and Chun-Fang Wu \\ Department of Biology, University of lowa, lowa City, lowa 52242
}

\begin{abstract}
A culture system of "giant" Drosophila neurons derived from cytokinesis-arrested embryonic neuroblasts was developed to overcome the technical difficulties usually encountered in studying small Drosophila neurons. Cytochalasin B-treated neuroblasts differentiated into giant multinucleated cells that displayed neuronal morphology and neuron-specific markers (Wu et al., 1990). Here, we report that these giant neurons express different excitability patterns and membrane channels similar to those reported in excitable tissues of Drosophila. Individual neurons exhibited distinct all-ornone or graded voltage responses upon current injection. Both current- and voltage-clamp recordings could be performed on the same neuron because of the large cell size, thus making it possible to elucidate the functional role of the individual types of channels. By using pharmacological agents and ion substitution, the following currents were identified in these giant neurons: inward $\mathrm{Na}^{+}$and $\mathrm{Ca}^{2}$ currents and outward voltage-activated (the A-type and delayed rectifier) and $\mathrm{Ca}^{2+}$-activated $\mathrm{K}^{+}$currents. In addition, we found a tetrodotoxin (TTX)-sensitive, $\mathrm{Na}^{+}$-dependent outward $\mathrm{K}^{+}$ current and a persistent component of an inward $\mathrm{Na}^{+}$current, which have not been reported in Drosophila previously. This culture system can be used to analyze the mutational perturbations in ion channels and the resultant alterations in membrane excitability. Neurons from the mutant slowpoke (s/o), which is known to lack a component of the $\mathrm{Ca}^{2+}$-activated $\mathrm{K}^{+}$currents in muscles, exhibited prolonged action potentials associated with defects in the $\mathrm{Ca}^{2+}$-activated $\mathrm{K}^{+}$ current. This abnormality appeared to be more severe in the neurites than in the soma.
\end{abstract}

A growing number of genes important to the nervous system have been studied in Drosophila melanogaster (Hall, 1982). Genetic manipulation provides useful tools to analyze physiological functions of ion channels and to identify the genes important in controlling membrane electrical activities. However, our knowledge of mutational effects on membrane excitability in Drosophila is mainly based on studies of muscle membrane

\footnotetext{
Received Oct. 26, 1990; revised Feb. 14, 1991; accepted Feb. 18, 1991

We thank Drs. E. Shibata and R. Wachtel for comments on the manuscript, Ms. G. Folkins for preparation of the manuscript, and Mr. P. Taft for technical assistance. This work was supported by NIH Grants NS 18500, NS 26528, and HD 18577.

Correspondence should be addressed to Dr. Mitsuyoshi Saito at the above address.

Copyright (C) 1991 Society for Neuroscience $0270-6474 / 91 / 112135-16 \$ 03.00 / 0$
}

(Ganetzky and Wu, 1986; Salkoff and Tanouye, 1986; Papazian et al., 1988; Wu and Ganetzky, 1988). To understand the genetic control of ion channel function in neurons, it is necessary to compare membrane properties in normal and mutant neurons. Such information may provide insights into problems unique to the nervous system, for example, neuronal integration and plasticity.

Because of technical difficulties, relatively few intracellular recordings have been obtained from Drosophila neurons in situ. Intracellular action potentials wcrc first recorded by Ikeda and Kaplan (1970) from the thoracic ganglion to show a defect in Hyperkinetic mutant flies. The effects of Shaker mutations on action potentials in the cervical giant fibers have also been characterized (Tanouye et al., 1981; Tanouye and Ferrus, 1985). Recently, dissociated neuronal culture systems have been used to allow patch-clamp analysis of embryonic (Byerly and Leung, 1988; O'Dowd and Aldrich, 1988; O'Dowd et al., 1989), larval (Wu et al., 1983; Sun and Wu, 1985; Solc et al., 1987; Solc and Aldrich, 1988), and pupal (Baker and Salkoff, 1990) neurons. However, there has been no study correlating current- and voltage-clamp results to determine the functional role of the different currents, presumably because action potentials in these small cells are extremely susceptible to internal dialysis by the electrode solution.

In order to facilitate the study of Drosophila neuronal function, we have developed a "giant neuron" culture system (Wu et al., 1990). Embryonic neuroblasts treated with cytochalasin B differentiated without cytokinesis into multinucleated giant cells with well-developed neurites. The giant neurons developed membrane excitability and expressed insect neuron-specific molecules (Wu et al., 1990). The use of these neurons allowed us to study active membrane responses such as action potentials and to correlate them with underlying current components.

In this study, we characterized the giant neurons using both current- and voltage-clamp methods to investigate two questions: first, whether the various ion channels underlying neuronal excitability are differentiated in the absence of cell divisions, and, second, whether the expression of mutations perturbing ionic channels can be analyzed in this culture system.

Some of the results described here have appeared in abstract form (Saito and $\mathrm{Wu}, 1989,1990)$.

\section{Materials and Methods}

Cell culture. The culture method was similar to that described previously (Seecof et al., 1971; Salvaterra et al., 1987; Wu et al., 1990). Briefly, dissociated cells were prepared from early gastrulas of Drosophila melanogaster. Embryos were collected on agar plates ( $1-2 \mathrm{hr}$ ) and incubated for $3.5 \mathrm{hr}$ at $25^{\circ} \mathrm{C}$. To remove the chorionic membrane, embryos were 
treated with clorox $/ 90 \%$ ethanol (1:1 by vol) solution for $1 \mathrm{~min}$ and then washed with $90 \%$ ethanol. After wash, embryos were homogenized in modified Schneider medium supplemented with $20 \%$ fetal bovine serum (FBS), $200 \mathrm{ng} / \mathrm{ml}$ insulin, penicillin $(50 \mathrm{U} / \mathrm{ml})$, and streptomycin $(50 \mu \mathrm{g} / \mathrm{ml})$. To remove debris, dissociated cells were washed in the same medium and then collected by centrifugation ( $2500 \mathrm{rpm}$ for $2 \mathrm{~min}$ ). After being washed twice, cells were resuspended in medium containing $2 \mu \mathrm{g} / \mathrm{ml}$ cytochalasin B and plated on glass coverslips. Cultures were kept in humidified chambers at room temperature $\left(20-23^{\circ} \mathrm{C}\right)$. In most cases, cultures were washed to remove cytochalasin B on the second day. However, membrane excitability in giant neurons did not show detectable changes with or without the removal of cytochalasin B. A great majority of cells (more than $80 \%$ ) that grew in cytochalasin Btreated cultures showed neuronal morphology. Cytochalasin B and insulin were from Sigma. Modified Schneider medium, FBS, penicillin, and streptomycin were from Gibco (Grand Island, NY).

Solutions and chemicals. For recording, cells on the coverslip were transferred to the bath solution containing (in $\mathrm{mM}$ ) $128 \mathrm{NaCl}, 2 \mathrm{KCl}$, $4 \mathrm{MgCl}_{2}, 1.8 \mathrm{CaCl}_{2}$, and 35.5 sucrose, buffered with $5 \mathrm{HEPES}$ at $\mathrm{pH}$ 7.1-7.2. To study the effects of $\mathrm{Co}^{2+}$ and $\mathrm{Ba}^{2+}$ on $\mathrm{Ca}^{2+}$ channels, these ions were substituted for $\mathrm{Ca}^{2+}$ in the bath solution, unless otherwise noted. $\mathrm{Na}^{+}$-free or $\mathrm{K}^{+}$-free solutions contained equimolar Tris-Cl in place of $\mathrm{NaCl}$ or $\mathrm{KCl}$. For current-clamp recording or for voltage-clamp recording of outward currents, patch pipettes were filled with solution containing (in mM) $144 \mathrm{KCl}, 1 \mathrm{MgCl}_{2}, 0.5 \mathrm{CaCl}_{2}$, and 5 EGTA, buffered with 10 HEPES at pH 7.1-7.2. In voltage-clamp studies of inward $\mathrm{Na}^{+}$ and $\mathrm{Ca}^{2+}$ currents, $\mathrm{CsCl}$ was used as a substitute for $\mathrm{KCl}$ to remove $\mathrm{K}^{+}$ currents. Tetraethylammonium chloride(TEA) was added to the bathing solution without adjusting an osmotic change. Tetrodotoxin (TTX) and 4-aminopyridine (4-AP) were obtained from Sigma (St. Louis, MO). TEA was from Kodak (Rochester, NY).

Whole-cell recording and data analysis. Patch pipettes were made from glass capillaries (75- $\mu$ l micropipettes, VWR, Chicago, IL) using a micropipette puller (model PP-83, Narishige, Tokyo, Japan) and fire polished with a microforge (model MF-83, Narishige). They were coated with Sylgard (184 silicon elastomer kit, Dow Corning, Midland, MI) to reduce stray capacitance. The tip opening of the patch pipette was about $1.2 \mu \mathrm{m}$, giving a resistance between 3 and $5 \mathrm{M} \Omega$ when filled with the solutions. Whole-cell recordings were made mainly from neurons 9-12 $\mu \mathrm{m}$ in diameter using an Axon patch clamp (Axo-Patch 2B, Axon Instruments, Foster City, CA). Junction potentials were nulled just prior to gigaohm seal formation. Generation of current and voltage pulse paradigms and data collection were performed by using an IBM XT computer with the pcLAMP software program (version 5.03, Axon) and A/D and D/A converters (Labmaster, Axon). Unless otherwise noted, the membrane potential $(V)$ was maintained at $-55 \pm 4 \mathrm{mV}$ in the current-clamp studies and held at $-80 \mathrm{mV}$ in the voltage-clamp studies. Current- and voltage-clamp data were first filtered at $2 \mathrm{kHz}$ (4-pole Bessel filter) and were digitized at 2-5 kHz. Except for experiments involving inactivating prepulses (shown in Figs. $4 B, 5,6$ ), leakage and capacitive currents that could not be compensated electronically were digitally subtracted. This was achieved either by subtracting from the total current the linear current component scaled up from that induced by a $10-$ or $20-\mathrm{mV}$ depolarization or, in some experiments, by using the $\mathrm{P} / 4$ protocol in the pCLAMP software.

In order to determine series resistance and whole-cell capacitance, a sequence of three voltage pulses stepping from -55 to $-45 \mathrm{mV}$ were applied immediately after establishing the whole-cell configuration. In some cells, the depolarizing pulses were applied from a more hyperpolarized potential to avoid eliciting active currents. The series resistance and membrane capacitance were calculated from the initial peak amplitude and the decay time constant of the averaged current trace. The average value of series resistance was $23.4 \pm 9.1 \mathrm{M} \Omega$ (mean $\pm \mathrm{SD}$; $n=39$ ). Series resistance compensation was about $40 \%$ in most experiments. Thus, in typical experiments, the error in membrane voltage measurements that resulted from the series resistance for a maximum current of $500 \mathrm{pA}$ was estimated to be less than $10 \mathrm{mV}$. Seal resistance exceeded 5 (up to 50 ) G $\Omega$ before the rupture of the patch membrane. Neurons generally had an input resistance exceeding $800 \mathrm{M} \Omega$ (typically $1-4 G \Omega$ ) at rest, and this value decreased considerably in the presence of active currents. The average value of whole-cell capacitance determined in this manner was $38.5 \pm 21.8 \mathrm{pF}$ (mean $+\mathrm{SD} ; n=39$ ). This value is almost 10 times larger than that estimated for spherical cells of similar soma diameters (9-12 $\mu \mathrm{m})$, assuming a unit membrane capacitance of $1 \mu \mathrm{F} / \mathrm{cm}^{2}$. This indicates that a considerable portion of the membrane area is attributable to neurites, which makes it difficult to achieve space-clamp conditions. In order to minimize the complications from the unclamped neurite membrane, we collected voltage-clamp data for quantitative analysis from cells of simple, similar morphology, that is, monopolar neurons with a shorter neurite. (More than $70 \%$ of current traces shown are from this type.) To determine the current-voltage (I$V$ ) relation, the current density at different voltages was obtained by dividing current amplitude by membrane capacitance $(\mathrm{pA} / \mathrm{pF})$. Theoretical curve fitting for steady-state inactivation data (see Eq. 1, Fig. 5) was performed by using the sigmaplot software (version 4.0, Jandel Scientific, Corte Madera, CA), which employs the Marquardt-Levenberg algorithm. All recordings were made at room temperature (20$23^{\circ} \mathrm{C}$ ).

\section{Results}

As previously shown (Wu et al., 1990), Drosophila neuroblasts treated with cytochalasin B became multinucleated cells that displayed large soma (9-12 $\mu \mathrm{m}$ in diameter, as compared to 3$8 \mu \mathrm{m}$ in untreated cultures) and well-developed neurites $1 \mathrm{~d}$ after plating (Fig. 1). Further growth of these neurons mainly involved lengthening and thickening of neurites with little change in the number of primary neurites. Figure 2 shows the distribution of neurons with regard to the number of their primary neurites compiled from cultures of different ages $(>1 \mathrm{~d})$. The majority of cells developed into monopolar neurons, which were most often used in this study (see Materials and Methods). Dissociated embryonic or larval neurons generally developed considerable swelling in the whole-cell configuration soon after the rupture of patch membrane, presumably due to internal dialysis by the patch pipette solution. In contrast, the soma of giant neurons usually showed little distortion in shape, even after completing the whole-cell clamp experiments (Fig. 1).

\section{Outward and inward currents and their functional roles \\ Identification of the A-type current and its function}

A large proportion of cells in this culture system developed allor-none regenerative action potentials (see below). When the membrane potential was preconditioned at a level more negative than $-55 \mathrm{mV}$, a significant delay was observed in actionpotential initiation in response to positive current injection (Fig. 3). Depolarizing (or hyperpolarizing) current pulses before the stimulus pulse shortened (or lengthened) the delay of actionpotential onset (Fig. 3A). This suggests the presence of an inactivating outward current that counterbalances the inward currents and thus delays action-potential onset. It is known that a transient outward $\mathrm{K}^{+}$current, called A-current, may play a role in this process. Prepulses can influence the level of A-current inactivation to modify the delay in action-potential initiation (Getting, 1983; Salkoff and Wyman, 1983). After current-clamp study, the neuron was examined for the presence of an inactivating outward current using the voltage-clamp method. We observed a prominent inactivating outward current that masked inward currents in this particular cell (Fig. 3C).

The following voltage-clamp experiments were performed to identify and characterize the A-type current in other cells: TTX $\left(10^{-8} \mathrm{M}\right)$ and $\mathrm{Co}^{2+}$ (replacing $\mathrm{Ca}^{2+}$ ) were used to eliminate $\mathrm{Na}^{+}$and $\mathrm{Ca}^{2+}$-dependent currents (see below). Figure $4 A$ shows the families of current traces before and after application of $2 \mathrm{~mm}$ 4-AP, which is known to block the A-current (Rudy, 1988). The difference between these two families of current traces gave the 4-AP-sensitive component, which showed the voltage dependence and inactivation rate typical of the A-type current (Fig. $4 C$ ). Before the application of 4-AP, a similar current component could also be demonstrated in the same cell by using inactivating prepulses. Experiments were carried out using a test 

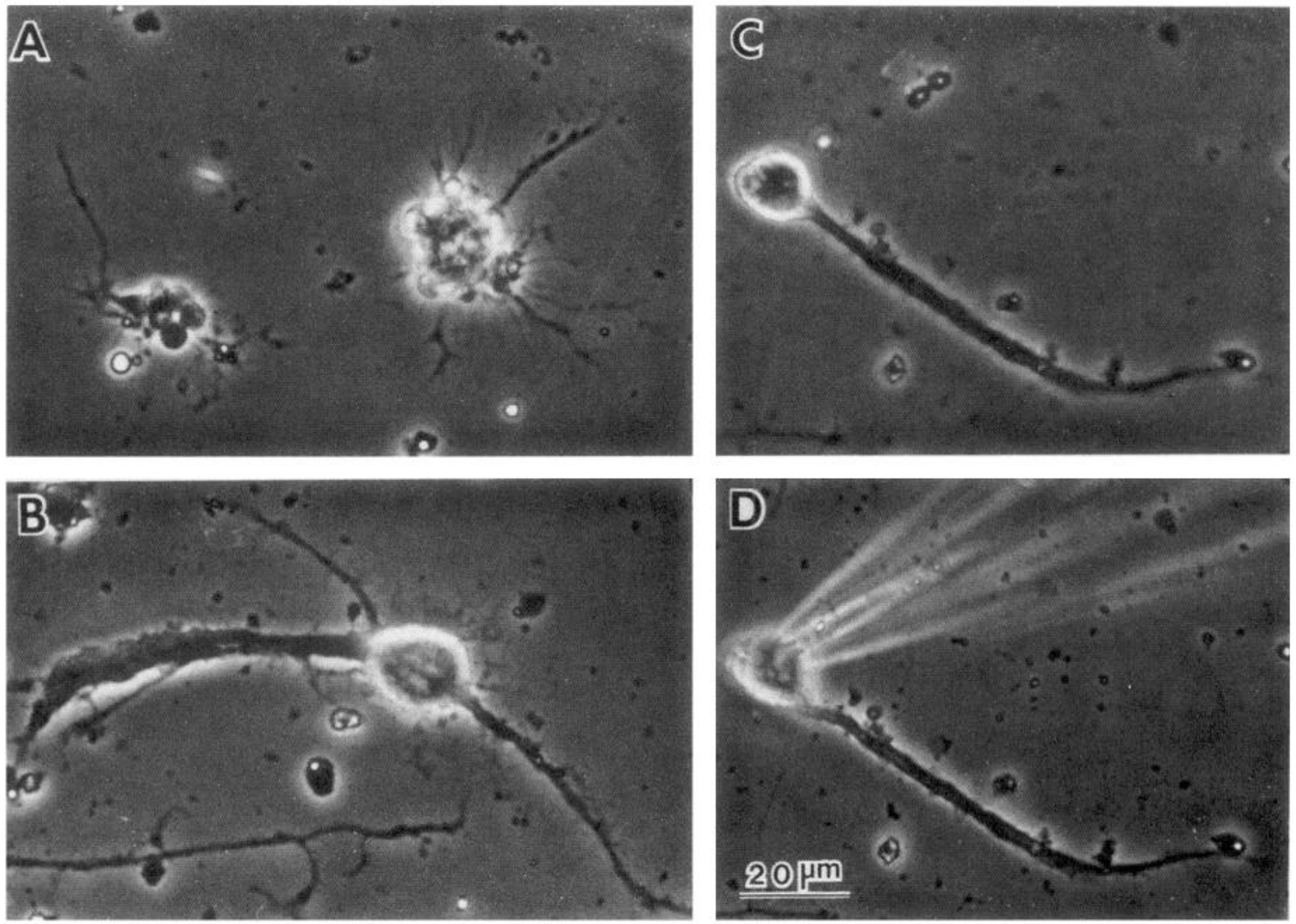

Figure 1. Drosophila giant neurons derived from cytochalasin B-treated embryonic neuroblasts. $A$, Neuronal clusters in normal dissociated embryonic cultures. Dissociated neuroblasts undergo asymmetric divisions and individually give rise to clusters of daughter cells ( $2 \mathrm{~d}$ in culture). $B$, Giant neurons differentiated from cell division-arrested neuroblasts. In cytochalasin B-treated cultures, individual neuroblasts grow into large single neurons with thicker neurites ( $3 \mathrm{~d}$ in culture). $C$ and $D$, Comparison of cell morphology before $(C)$ and after $(D)$ recording. Whole-cell clamp recording caused no substantial change in morphology ( $4 \mathrm{~d}$ in culture).

pulse from different preconditioning voltages to $-20 \mathrm{mV}$, at which activation of the delayed-rectifier $\mathrm{K}^{+}$current was minimized (see below). The test pulse evoked a maximum A-type current when the membrane was preconditioned at $-100 \mathrm{mV}$. In contrast, the transient current was totally inactivated at -40 $\mathrm{mV}$ and could not be elicited by the test pulse (Fig. $4 B$ ). Figure $4 D$ shows the steady-state inactivation of the transient current, that is, the ratio of the remaining current $(I)$ at different preconditioning voltages over the maximum attainable current $\left(I_{0}\right.$, at $-100 \mathrm{mV}$ ). The midpoint of steady-state inactivation in this particular neuron was about $-70 \mathrm{mV}$. The $I-V$ relation of the 4-AP-sensitive current was also plotted in Figure $4 D$, which indicates that this current could be inactivated at voltages where little or no activation occurs. The 4-AP sensitivity of this current has been confirmed in four other neurons, and the voltagedependent inactivation has been observed in a number of neurons (see below).

There is evidence suggesting that at least two kinds of the A-type currents exist in Drosophila. In embryonic cultures, the voltage ranges of inactivation and activation of the A-type current in myotubes differ from those in neurons (Solc et al., 1987). In addition, inhomogeneity of A-current has been indicated in dissociated pupal neurons (Baker and Salkoff, 1990).

We sampled a number of cells to examine whether different A-type currents exist in subpopulations of giant neurons. We noticed significant variation in the voltage range in which the A-type current became inactivated (Fig. 5). Experiments were carried out using a test pulse to $-20 \mathrm{mV}$, as described above. The steady-state inactivation for each neuron could be described by Equation 1, derived from the Boltzmann distribution (Hille, 1984):

$$
I / I_{0}=1 /\left(1+\exp \left(\left(V-V_{h}\right) / S\right)\right)
$$

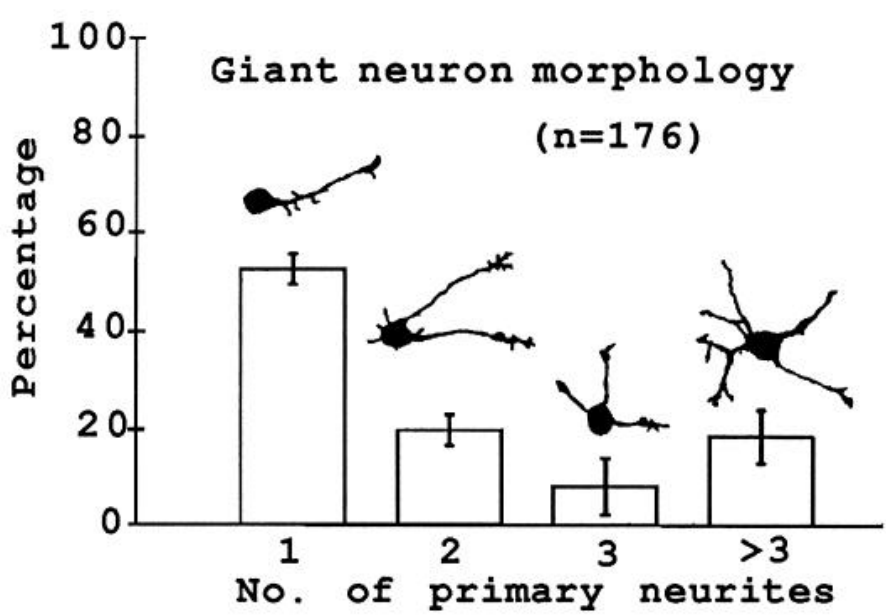

Figure 2. Morphology of Drosophila giant neurons. Graph shows the distributions of giant neurons classified according to the number of primary neurites. (Data from three different cultures. Error bars indicate SD.) 


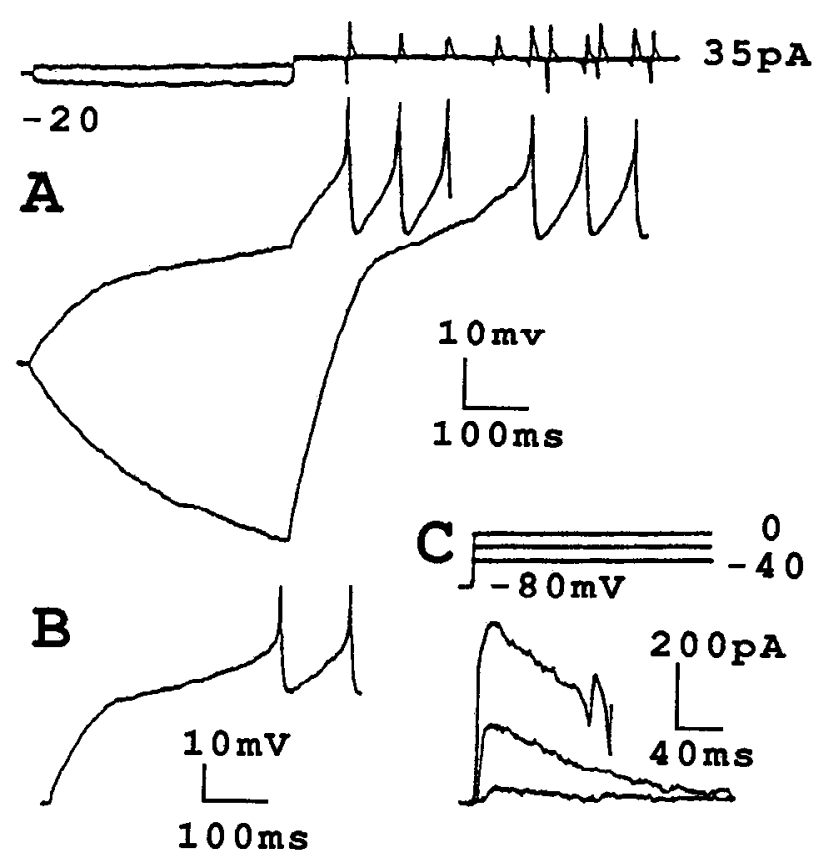

Figure 3. Effect of the A-type transient current on the onset of action potentials observed in current-and voltage-clamp records from the same neuron. $A$, The delay of action-potential onset (injection of $+35 \mathrm{pA}$ ) was shortened by a depolarizing prepulse (injection of $+20 \mathrm{pA}$ ), which presumably inactivated the A-type current, but prolonged by a hyperpolarizing prepulse (injection of $-20 \mathrm{pA}$ ), which removed inactivation of the A-type current. $V_{r}=-65 \mathrm{mV} . B$, Injection of depolarizing currents $(40 \mathrm{pA})$ caused gradual membrane depolarization and finally elicited action potentials. $V_{r}=-62 \mathrm{mV}$. $C$, In voltage-clamp experiments, prominent transient outward currents similar to the A-type current were elicited by depolarization steps $(-40$ to $0 \mathrm{mV}$ ) from a holding potential $\left(V_{H}\right)$ of $-80 \mathrm{mV}$. where $V$ stands for the preconditioning voltage; $V_{h}$, the midpoint (voltages at which $50 \%$ of the current is inactivated); and $S$, the slope factor (which reflects the voltage sensitivity of channel inactivation). Among seven cells studied in the presence of TTX and $\mathrm{Co}^{2+}, V_{h}$ varied from -80 to $-44.8 \mathrm{mV}$ with a mean \pm SD of $-65.3 \pm 11.0 \mathrm{mV}$ (Fig. 5). $S$ ranged from 4.1 to $8.0 \mathrm{mV}$ $(5.9 \pm 1.1 \mathrm{mV})$. These values are within the ranges previously reported for the A-type currents in cultured larval and pupal neurons (Solc et al., 1987; Baker and Salkoff, 1990). Similar variation in $V_{h}$ (ranging from -84.5 to $-51.7 \mathrm{mV}$ ) has been obscrved in 13 additional neurons. Results from these neurons were excluded from the above analysis because the experiments were performed without TTX in the bath (see Figs. 11, 12).

\section{Delayed-rectifier $K^{+}$current}

Another voltage-activated outward current usually encountered in giant neurons showed kinetics similar to that of the conventional delayed-rectifier $\mathrm{K}^{+}$current (Fig. $6 A$ ). TTX and $\mathrm{Co}^{2+}$ were present to block $\mathrm{Ca}^{2+}$ - and $\mathrm{Na}^{+}$-dependent currents. A sustained outward current could be isolated by applying 4-AP (Fig. 4A, broken line) or by manipulating the holding potential to inactivate the A-type current (Fig. $6 A$ ). The $I-V$ relation of this sustained current is shown in Figure $6 B$. This current was activated at membrane potentials more positive than $-30 \mathrm{mV}$ and did not inactivate appreciably during the depolarizing pulse (up to $300 \mathrm{msec}$ at $0 \mathrm{mV}$ ). From tail-current experiments, the reversal potential was estimated to be $-74.6 \pm 3.6 \mathrm{mV}(n=5)$ with normal $\mathrm{K}^{+}$concentration $(2 \mathrm{mM})$ in bath. The sensitivity to TEA of this current varied from neuron to neuron. In some cases, $20 \mathrm{~mm}$ TEA blocked only half of the current, while in other cases, the same concentration of TEA completely eliminated the outward current (data not shown).
Figure 4. Inactivation and 4-AP sensitivity of the A-type current. $A$, The solid traces show the total outward current activated by pulses from $V_{H}=-80$ to -50 to $+10 \mathrm{mV}$ in $20-\mathrm{mV}$ steps. Broken traces show after the addition of 2 mM 4-AP. $B$, Inactivation of the A-type currents elicited at $-20 \mathrm{mV}$ by 150 -msec prepulses $(-100$ to $-40 \mathrm{mV}$ in $20-\mathrm{mV}$ steps). $C, 4-\mathrm{AP}-$ sensitive current component. The differences in total outward currents between control (solid traces in $A$ ) and after treatment of $2 \mathrm{~mm}$ 4-AP (broken traces in $A$ ) are shown. $D, I-V$ relation (open squares; data from $C$ ) and steady-state inactivation (solid squares; data from $B$ ). In this and the following figures, current density in the $I-V$ relation was estimated by normalizing current amplitude to membrane capacitance $(\mathrm{pA} / \mathrm{pF})$. Steady-state inactivation was determined by the ratio of the remaining current $(I)$ at different preconditioning voltages over the maximum attainable current $\left(I_{0}\right.$, at $\left.-100 \mathrm{mV}\right)$. All data were taken from the same cell. The bath solution contained TTX $\left(10^{-8} \mathrm{M}\right)$ and $\mathrm{Co}^{2+}$ in place of $\mathrm{Ca}^{2+}$.

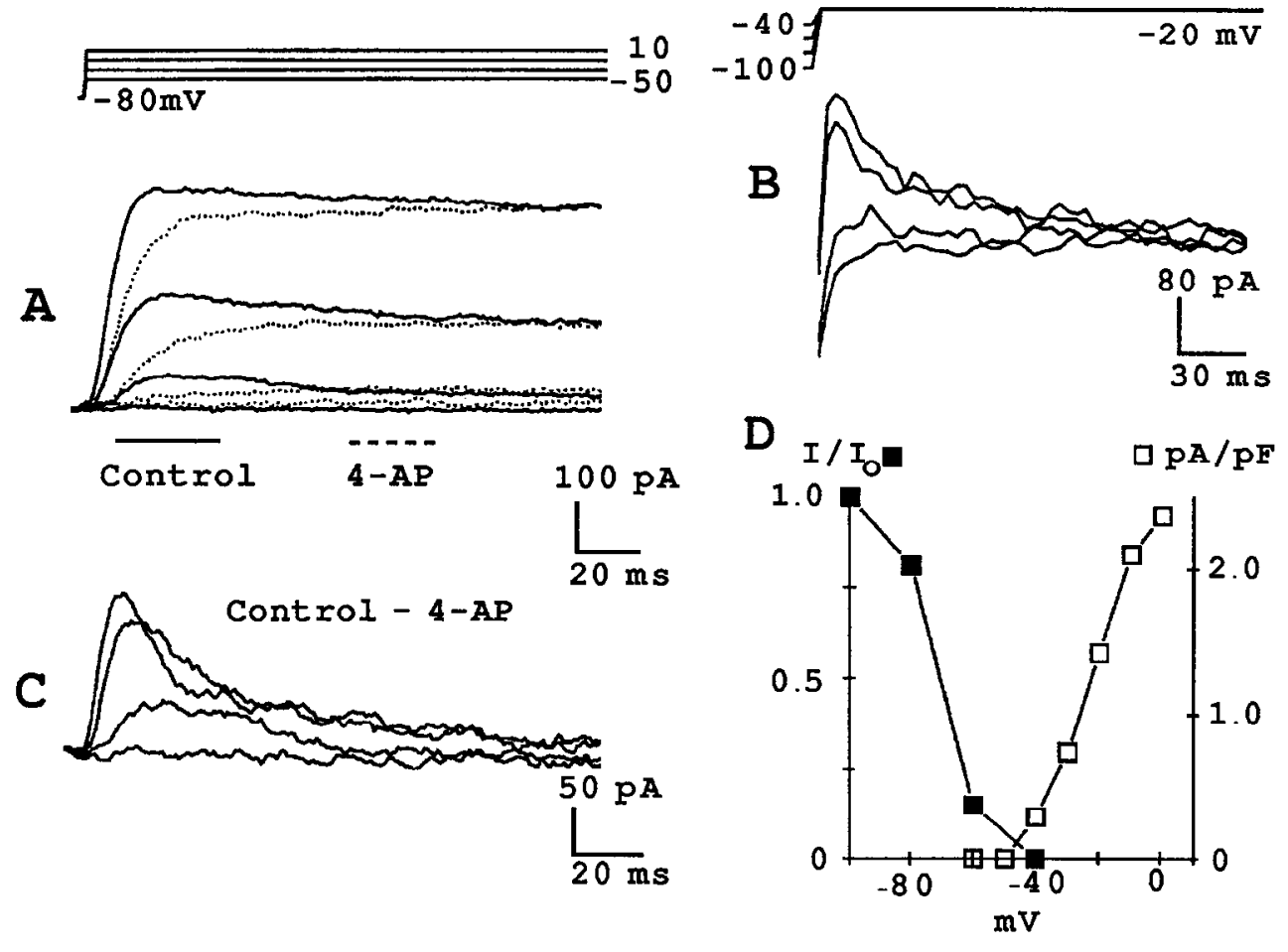



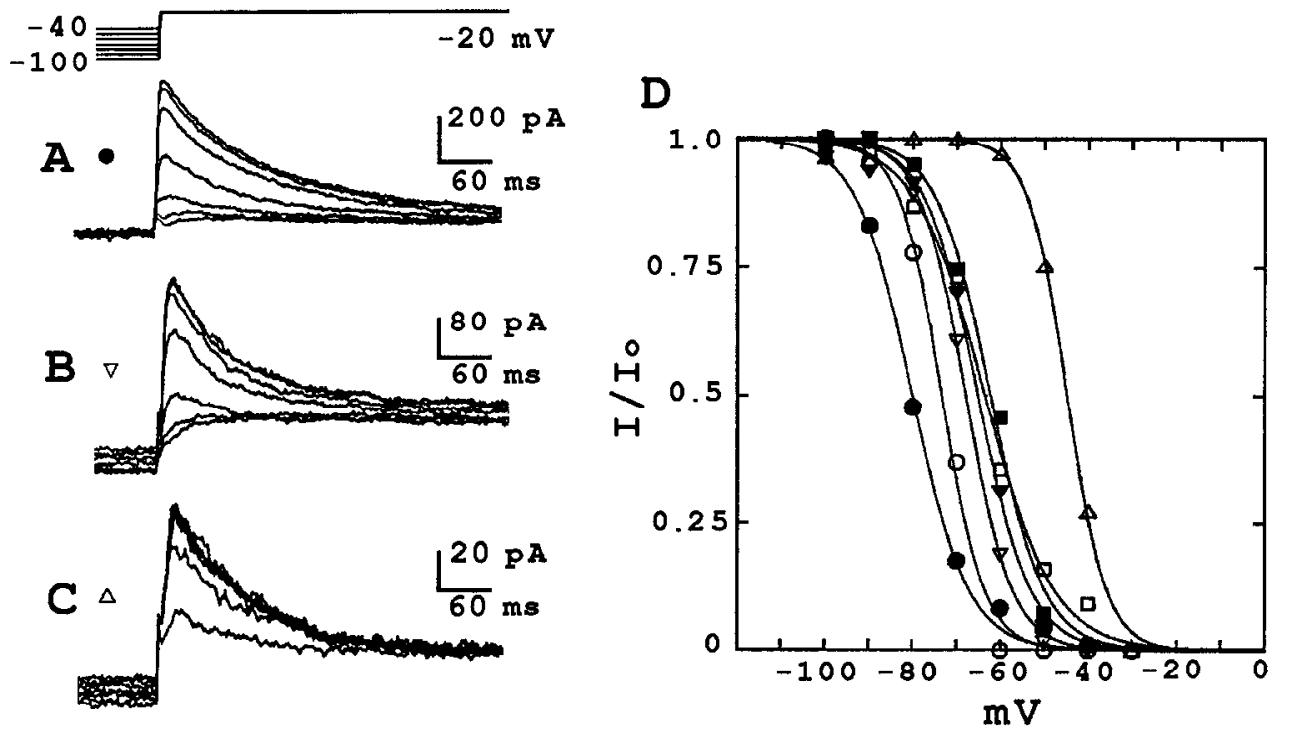

Figure 5. Variation in steady-state inactivation of the A-type current. $A-C$, Examples of voltage-clamp traces from three different cells in which inactivation occurred in different voltage ranges. Steady-state inactivation was determined by applying preconditioning voltage pulses ( $500 \mathrm{msec} ;-100$ to -40 $\mathrm{mV}$ in $10-\mathrm{mV}$ steps) that preceded the test pulse to $-20 \mathrm{mV}$. The A-type current in $A$ inactivated at a more negative potentials with a midpoint $V_{h}=-80.0$ $\mathrm{mV}$, compared with the currents shown in $B\left(V_{h}=-67.9 \mathrm{mV}\right)$ and $C\left(V_{h}=\right.$ $-44.8 \mathrm{mV}) . D$, Steady-state inactivation $\left(I / I_{0}\right)$ of the A-type current at different preconditioning voltages. Each symbol represents a different cell. Data from the cclls shown in $A-C$ (symbols on the left side of traces $A-C$ ) were also plotted in this graph. The current amplitude ( $I$ and $\left.I_{0}\right)$ was measured as the difference between the peak and the remaining current at the end of the test pulse following the most positive prepulse.

\section{Effects of $\mathrm{K}^{+}$channel blockers on action potentials and the outward current}

Because giant neurons allowed performing current- and voltageclamp recordings on the same cell, the effects of $\mathrm{K}^{+}$channel blockers on action-potential properties were first studied under current clamp, and the outward currents responsible for the change were further examined under voltage clamp. In the cell shown in Figure $7 A, 20 \mathrm{~mm}$ TEA in normal saline lowered the current required to initiate action potentials. It also prolonged the duration of action potentials and induced repetitive firing during sustained current injection (Fig. $7 A_{2}$ ). Addition of $2 \mathrm{mM}$ 4-AP further prolonged the action potential and induced a plateau at its falling phase (Fig. $7 A_{3}$ ). In the presence of TEA and 4-AP, the same neuron in voltage-clamp mode showed initial inward currents followed by outward currents (Fig. $7 B_{1}$ ). Apparently, TEA and 4-AP reduced $\mathrm{K}^{+}$outward currents, including the A-type current and delayed rectifier, and unmasked the inward currents responsible for the action potential. The recording solution was subsequently changed to normal saline (Fig. $7 B_{2}$ ). Subtracting $B_{1}$ from $B_{2}$ gives the 4-AP- and TEA-sensitive currents (Fig. $7 B_{2}-B_{i}$ ), which show both transient and sustained outward components. This experiment suggests that both current components contribute to action-potential repolarization.

\section{$\mathrm{Na}^{+}$and $\mathrm{Ca}^{2+}$ inward currents}

Because the blocking efficiency of TEA varied from neuron to neuron, outward $\mathrm{K}^{+}$currents were blocked by using patch pipettes filled with $\mathrm{CsCl}$ instead of $\mathrm{KCl}$ (Armstrong and Bezanilla, 1973). The remaining whole-cell currents consisted of mainly inward currents under this condition. The $\mathrm{Na}^{+}$current was observed with either $\mathrm{Co}^{2+}$ in place of $\mathrm{Ca}^{2+}$ in bath to block the $\mathrm{Ca}^{2+}$ current or subtraction of current recorded in $\mathrm{Na}^{+}$- and $\mathrm{K}^{+}-$ free saline from that in $\mathrm{K}^{+}$-free saline. The $\mathrm{Na}^{+}$current could be activated by pulses to around $-40 \mathrm{mV}$. A maximum peak current was elicited by a pulse to between -20 and $0 \mathrm{mV}$ (Fig. $8 A$ ). Among 19 neurons studied, six of them showed a typical inward $\mathrm{Na}^{+}$current with nearly complete inactivation (Fig. $8 A_{j}$ ). The inward current in the other neurons, however, exhibited a clear noninactivating component (Fig. $8 B_{i}$ ), which persisted during a 500-msec pulse. This persistent inward current was activated concurrently with the transient component and also peaked in a similar voltage range (Fig. $8 A_{2}, B_{2}$ ). It was most likely mediated by $\mathrm{Na}^{+}$channels because it was observed in $\mathrm{K}^{+}-$ free bath solution and was blocked by $10^{-8} \mathrm{M}$ TTX, as was the transient inward component (Fig. $\left.8 A_{t}, B_{l}\right)$. However, the per-
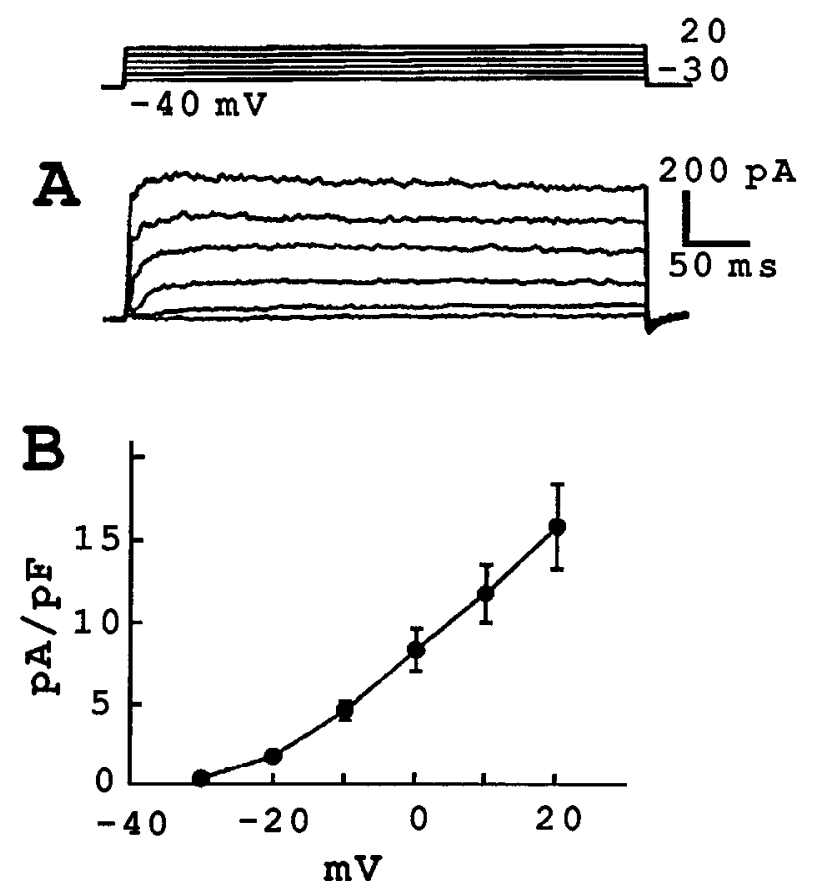

Figure 6. Delayed-rectifier-type outward current. $A$. Representative traces of delayed-rectifier outward $\mathrm{K}^{+}$current from a neuron in which the A-type current was totally inactivated by preconditioning at -40 $\mathrm{mV}(500 \mathrm{msec}) . B, I-V$ relation of delayed-rectifier currents. Data were pooled from four different neurons, in which the A-type current was removed by $-40-\mathrm{mV}$ preconditioned pulses. The experiments were carried out in the presence of TTX $\left(10^{-8} \mathrm{M}\right)$ and $\mathrm{Co}^{2+}(1.8 \mathrm{mM}$ in place of $\mathrm{Ca}^{2+}$ ). Error bars indicate SEM. 


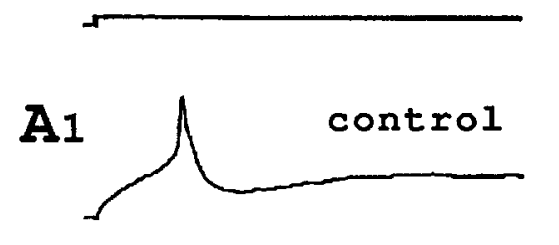

Figure 7. Effects of $\mathrm{K}^{+}$channel blockers on the action potentials and membrane currents in the same neuron. $A_{l}$, Control action potential. $A_{2}$, TEA (20 mM) prolonged action-potential duration. $A_{3}$, Subsequent addition of 4-AP ( $2 \mathrm{mM}$ ) further prolonged the action potential. $V_{r}=-50.3 \mathrm{mV}$ in $A_{1}$ and -56.2 $\mathrm{mV}$ in $A_{2}$ and $A_{3}$. Depolarizing current (36 pA) was injected in all experiments. $B_{i}$, In the subsequent voltage-clamp measurement, this neuron showed an inward current followed by an outward current in the presence of 4-AP and TEA. $B_{2}$, Total membrane current after washout of TEA and 4-AP. The difference between $B_{2}$ and $B_{1}\left(B_{2}-B_{1}\right)$ gives the 4-AP- and TEA-sensitive component. No TTX or $\mathrm{Co}^{2+}$ was present in this experiment. $V_{H}=-80 \mathrm{mV}$.
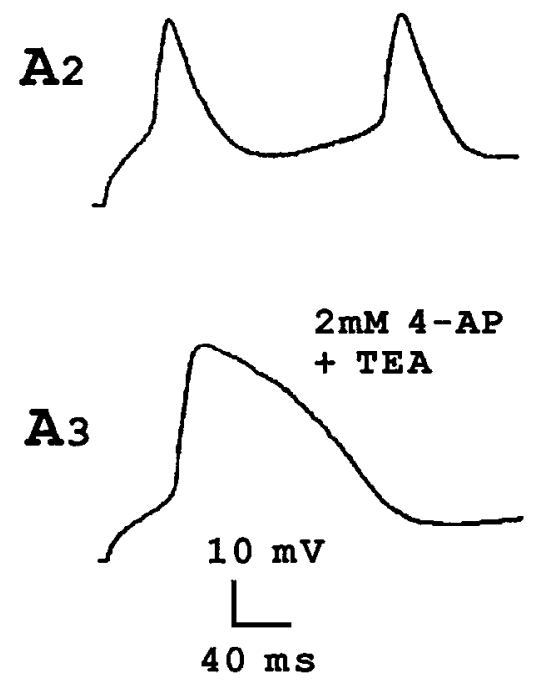
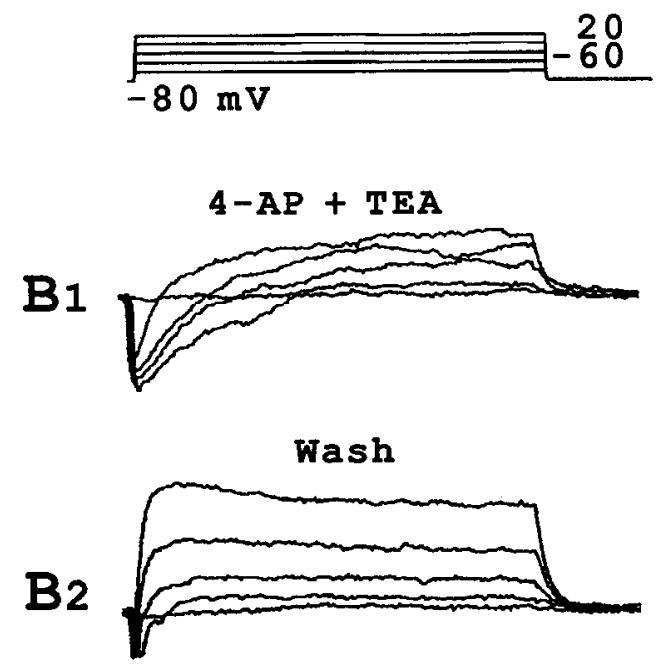

sistent current component might represent the activation of a separate population of $\mathrm{Na}^{+}$channels, because it was less sensitive than the transient component to inactivating prepulses (Fig. $8 C_{1}, C_{2}$ ). A $500-\mathrm{msec}$ preconditioning pulse to $-30 \mathrm{mV}$ inactivated more than $80 \%$ of the transient component but exerted little effect on the persistent component.

$\mathrm{Ca}^{2+}$ currents were studied with solution in which $\mathrm{Na}^{+}$was replaced with Tris-Cl (Byerly and Leung, 1988). The amplitude of $\mathrm{Ca}^{2+}$ current was much smaller than that of $\mathrm{Na}^{+}$current (cf. Fig. $8 A_{l}, B_{l} ; 9 A, B$ ). The $\mathrm{Ca}^{2+}$ current was consistently abolished by either replacing $\mathrm{Ca}^{2+}$ with $\mathrm{Co}^{2+}$ or adding 50-100 $\mu \mathrm{M} \mathrm{Cd}^{2+}$ or 100-200 $\mu \mathrm{M} \mathrm{La}{ }^{3+}$ to the bath (not shown). The $I-V$ relation for the peak $\mathrm{Ca}^{2+}$ current is shown in Figure $9 \mathrm{C}$. Some variation in kinetics was observed in the neurons studied (more than 20). Figure $9 A$ shows a $\mathrm{Ca}^{2+}$ current consisting of inactivating and noninactivating components. Another example is shown in Figure $9 B_{I}$, in which the inward current inactivated almost completely during the $100-\mathrm{msec}$ pulse. When $\mathrm{Ca}^{2+}$ was replaced with $\mathrm{Ba}^{2+}$, which is permeable through the $\mathrm{Ca}^{2+}$ channel, the resultant currents did not show any inactivation (Fig. 9 $B_{2}$ ). This is consistent with the report that inactivation of $\mathrm{Ca}^{2+}$ current could be associated with accumulation of internal $\mathrm{Ca}^{2+}$ (Tillotson, 1979).

\section{$\mathrm{Ca}^{2+}$-activated $\mathrm{K}^{+}$currents}

$\mathrm{Ca}^{2+}$-activated $\mathrm{K}^{+}$channels have been shown to regulate actionpotential repolarization and to modulate repetitive firing (Blatz and Magleby, 1987; Latorre et al., 1989). Replacing $\mathrm{Ca}^{2+}$ with $\mathrm{Co}^{2+}$ resulted in a delay in repolarization and a slight reduction in the hyperpolarizing afterpotential (Fig. 10A), both of which could be attributed to a block of $\mathrm{Ca}^{2+}$-activated outward current.

Under voltage-clamp conditions, the presence of $\mathrm{Ca}^{2+}$-acti- vated outward currents was reflected by a reduction, instead of an increase, in the net outward current when the inward $\mathrm{Ca}^{2+}$ current was blocked. Families of current data were collected before (Fig. $10 B$ ) and after $(C)$ replacing $\mathrm{Ca}^{2+}$ with $\mathrm{Co}^{2+}$. TTX $\left(10^{-8} \mathrm{M}\right)$ was used to block $\mathrm{Na}^{+}$inward current. The differences between Figure 10,B and $C$, consist of inward $\mathrm{Ca}^{2+}$ current and $\mathrm{Ca}^{2+}$-activated outward current. In the majority of neurons examined, except for a brief inward transient immediately following the depolarizing step, the inward current was overwhelmed by the ensuing outward currents (Fig. 10B,C). Because all outward currents were abolished by internal $\mathrm{Cs}^{+}$(cf. Figs. 8, 9), this outward component in the $\mathrm{Ca}^{2+}$-dependent current (Fig. 10B,C) is most likely carried by $\mathrm{K}^{+}$. The time course of the total current (Fig. 10B,C) also suggested the presence of a transient and a sustained phase in the $\mathrm{Ca}^{2+}$-activated outward current. The transient and sustained components were both activated at membrane potentials similar to the $\mathrm{Ca}^{2+}$ current (cf. Fig. 9). In 18 neurons examined, 15 showed net outward $\mathrm{Co}^{2+}$-sensitive currents. Among them, nine displayed a transient peak followed by a late component (e.g., Fig. 10D,E), and six showed no transient peak. The net total current in the remaining three neurons was inward during a depolarizing pulse (Fig. 10F).

\section{$T T X$-sensitive outward current}

TTX is thought to block specifically $\mathrm{Na}^{+}$channels (Narahashi et al., 1964; Hille, 1984). To our surprise, TTX not only abolished the $\mathrm{Na}^{+}$inward current, but also reduced the outward current in many of our experiments. Figure 11 shows one example in which the effects of TTX were studied with both current- and voltage-clamp techniques in the same cell. Current injection evoked action potentials that were completely blocked by TTX at $10^{-8} \mathrm{M}$ (Fig. $11 \mathrm{~A}$ ). In the subsequent voltage-clamp 

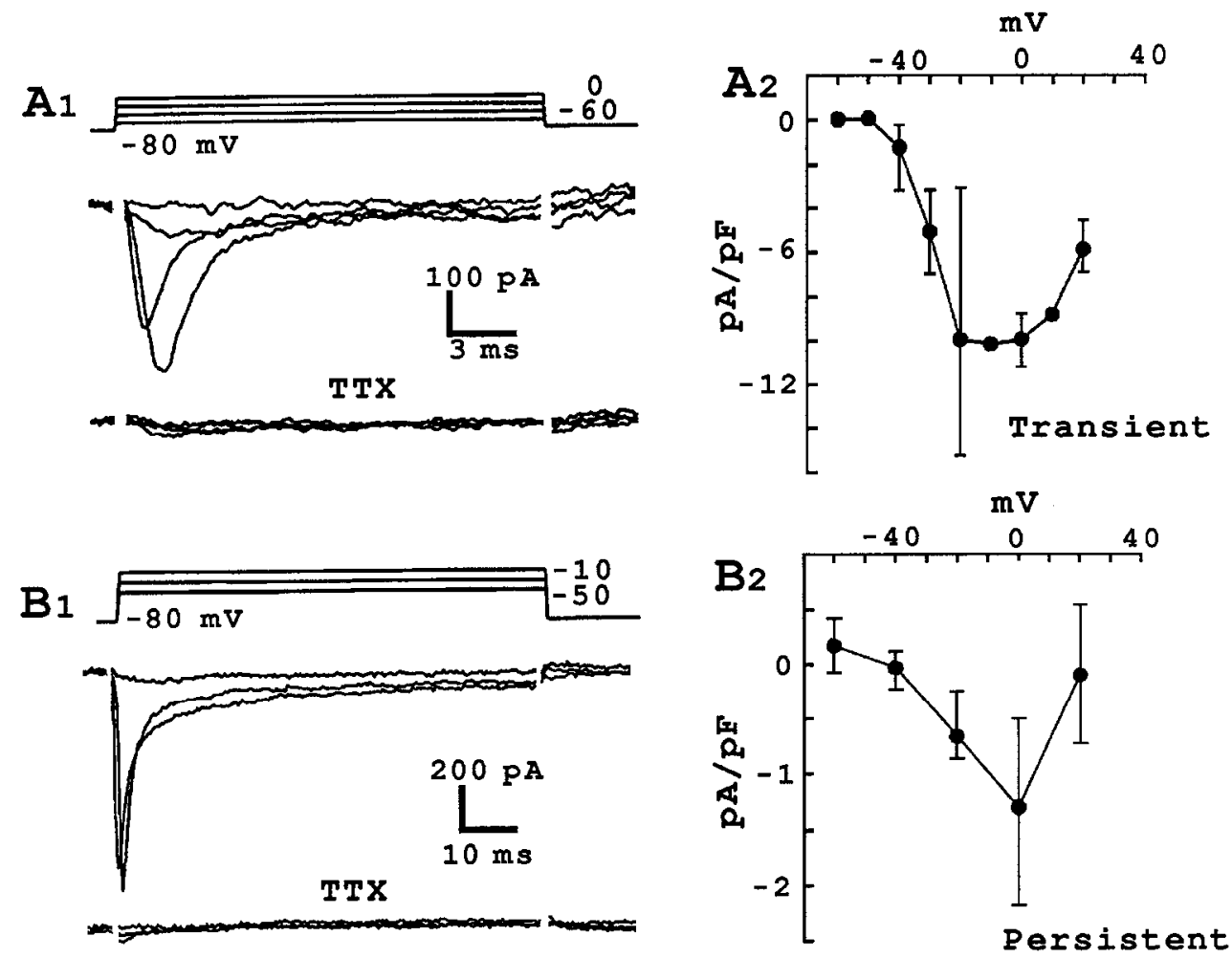

Figure 8. Voltage-activated $\mathrm{Na}^{+}$inward currents in $\mathrm{Ca}^{2+}$ - and $\mathrm{K}^{+}$-free saline. Patch pipettes were filled with $\mathrm{CsCl}$ to block $\mathrm{K}^{+}$current. $\mathrm{Ca}^{2+}$ current was blocked by the substitution of $\mathrm{Ca}^{2+}$ with $\mathrm{Co}^{2+} . A_{I}$ and $B_{I}$ were taken from two neurons with different proportions of transient and persistent components. Both components were blocked by $10^{-8}$ M TTX. $A_{2}, I-V$ relation of peak transient $\mathrm{Na}^{+}$currents. Data are from a different set of three neurons. $B, I-V$ relation of persistent $\mathrm{Na}^{+}$currents. Data are from three different neurons. $C_{l}$, Preconditioning at $-30 \mathrm{mV}(500 \mathrm{msec})$ inactivated only the transient component but not the persistent component. Broken line indicates the holding current level. $C_{2}$, Steady-state inactivation of the transient (solid circles) and persistent (open circles) $\mathrm{Na}^{+}$inward currents. Data are from two different neurons. Error bars in the graphs indicate the range. recording after TTX was washed out $(17 \mathrm{~min})$, there was recovery not only in the inward current, but also in the outward current. Further application of TTX again abolished the inward current and part of the outward current (cf. Fig. $11 B_{1}, B_{2}$ ). Both currents showed partial recovery after $2 \mathrm{~min}$ of wash (Fig. $11 B_{3}$ ). This TTX-sensitive outward current was observed in 11 out of 12 neurons that showed a clear initial inward component (e.g., Fig. $11 B_{I}$ ).

It is likely that the outward component blocked by TTX was activated by accumulation of internal $\mathrm{Na}^{+}$. The effect of reducing $\mathrm{Na}^{+}$influx by removal of $\mathrm{Na}^{+}$in the bath solution was therefore examined. Figure $12 A$ shows an example of reduction of external $\mathrm{Na}^{+}$that led to a decrease in the inward current and also in the outward current. Partial recovery of both inward and outward currents was observed after returning to normal saline. The majority of neurons examined (eight out of nine) showed a decrease in outward current amplitude after removal of $\mathrm{Na}^{+}$ from the recording solution. Consistent with the results of TTX treatment, removal of $\mathrm{Na}^{+}$in saline caused a 30-50\% reduction in outward current amplitude.

Previous reports (Dryer et al., 1989; Haimann et al., 1990) of $\mathrm{Na}^{+}$-activated $\mathrm{K}^{+}$current in other species have demonstrated that $\mathrm{Li}^{+}$can permeate $\mathrm{Na}^{+}$channels but does not activate this $\mathrm{K}^{+}$current. We studied the effect on giant neurons of replacing external $\mathrm{Na}^{+}$with $\mathrm{Li}^{+}$. In two out of three neurons, $\mathrm{Li}^{+}$decreased the outward current but left the inward current intact (Fig. 12B). The above results indicate that an $\mathrm{Na}^{+}$-activated $\mathrm{K}^{+}$current, similar to that described in other species (Bader et al., 1985; Dryer et al., 1989), appears to be present also in Drosophila neurons.

\section{Excitability in different cell categories}

Previous voltage-clamp studies indicate considerable inhomogeneity in membrane currents in cultured embryonic and larval 
Figure 9. Voltage-activated $\mathrm{Ca}^{2+}$ inward currents observed in $\mathrm{Na}^{+}$- and $\mathrm{K}^{+}$free saline with $\mathrm{CsCl}$-filled electrodes. $A$ and $B_{1}$ werc taken from two neurons with different proportions of transient and sustained components. $B_{2}, \mathrm{Ba}^{2+}$ current in the same neuron as in $B_{1}$ observed with $\mathrm{Ba}^{2+}$ in place of $\mathrm{Ca}^{2+}$ in saline. Note that $\mathrm{Ba}^{2+}$ removed channel inactivation. $C, I-V$ relation of peak $\mathrm{Ca}^{2+}$ inward currents. Data are from four different neurons. Error bars indicate SEM except for data points marked by asterisks, which show the range of two samples.
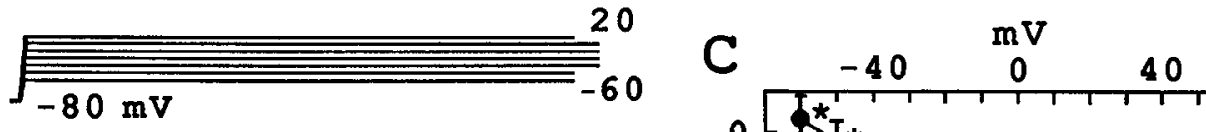

A
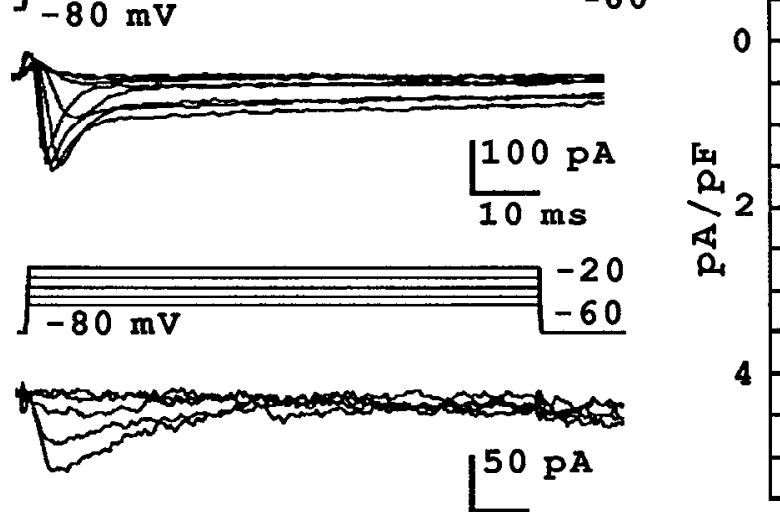

$B_{1}$

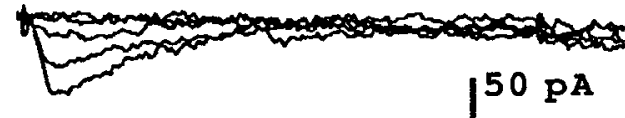

$10 \mathrm{~ms}$

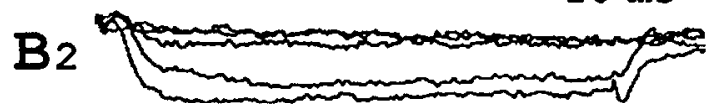

CNS neurons of Drosophila (Byerly and Leung, 1988; O'Dowd and Aldrich, 1988; Solc and Aldrich, 1988). Giant neurons derived from dissociated early gastrulas also exhibited variation in membrane currents under voltage clamp and various patterns of regenerative potentials under current clamp. We made an attempt to correlate the variety of membrane potentials with underlying currents.

\section{Categories of regenerative responses}

In current-clamp experiments, several distinct patterns of responses were induced by depolarizing current steps. From a total of 149 cells, we tentatively classified them into three major types according to properties of the regenerative membrane potentials: (1) All-or-none (62 out of 149). These neurons produced all-or-none action potentials with a clear threshold (Fig. 13A; see also Figs. 3, 7, 10, 11). (2) Graded. Regenerative potentials in this group of neurons increased in amplitude with increasing strength of the injected current. They could be further subdivided into two types. Some neurons (27 out of 149) displayed oscillations with either increasing or decreasing amplitudes [Fig. $13 B$, graded MP (graded, multiple peak)]. Other neurons (34 out of 149) in this group showed a single graded response only at the beginning of the current pulse [Figs. 4; 13C, graded SP (graded, single peak)]. The graded response varied in peak amplitude, and some could reach the size of all-or-none action potentials. However, they differed from all-or-none action potentials in that the depolarizing phase often lacked a clear inflection point and the repolarizing phase was less rapid. (3) Nonregenerative (26 out of 149). These cells showed outward rectification but no clear sign of regenerative potentials (data not shown).

Both $\mathrm{Ca}^{2+}$ and $\mathrm{Na}^{+}$inward currents can support membrane depolarization to generate spikes of different time courses. We
Figure 10. Current-and voltage-clamp studies of $\mathrm{Ca}^{2+}$-activated outward current. $A$, Substitution of $\mathrm{Co}^{2+}$ for $\mathrm{Ca}^{2+}$ in saline induced delay of action-potential repolarization, suggesting the presence of a $\mathrm{Ca}^{2+}$-activated $\mathrm{K}^{+}$current. The action potential was induced by $13-\mathrm{pA}$ constant depolarizing current. $B$, Voltage-clamp traces in the presence of TTX. $C$, Traces from the same neuron with $\mathrm{Ca}^{2+}$ substituted by $\mathrm{Co}^{2+}$ in saline containing TTX. $D$, Subtraction of $C$ from $B(B-C)$, representing $\mathrm{Ca}^{2+}$-dependent inward (arrow) and outward currents. Note the transient and delayed outward components. $E$ and $F$, Net $\mathrm{Co}^{2+}$-sensitive current extracted from two other wild-type neurons, illustrating variation in $\mathrm{Ca}^{2+}$. dependent current. Net inward currents were seen in a lew neurons $(F)$, suggesting a lack of $\mathrm{Ca}^{2+}$-activated $\mathrm{K}^{+}$currents. $G, \mathrm{Co}^{2+}$-sensitive currents from a slo neuron displaying purely inward currents.
A
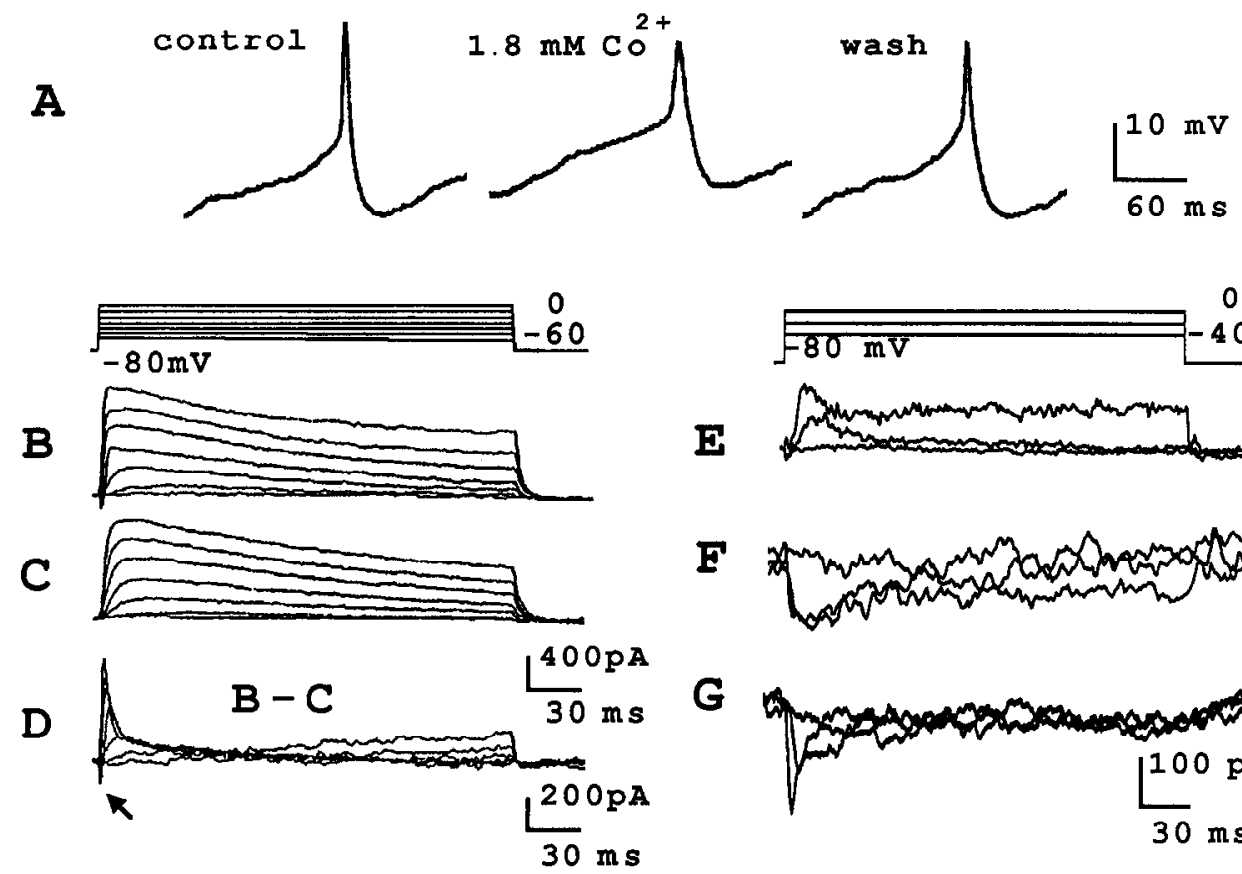

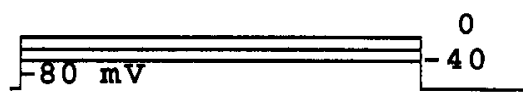

$\mathbf{E}$

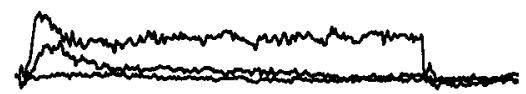

$\mathbf{F}$

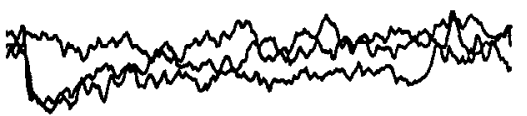

G

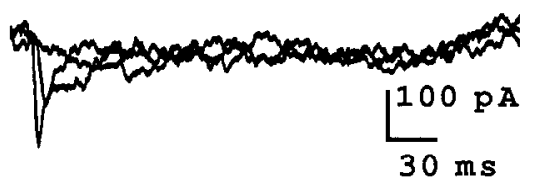



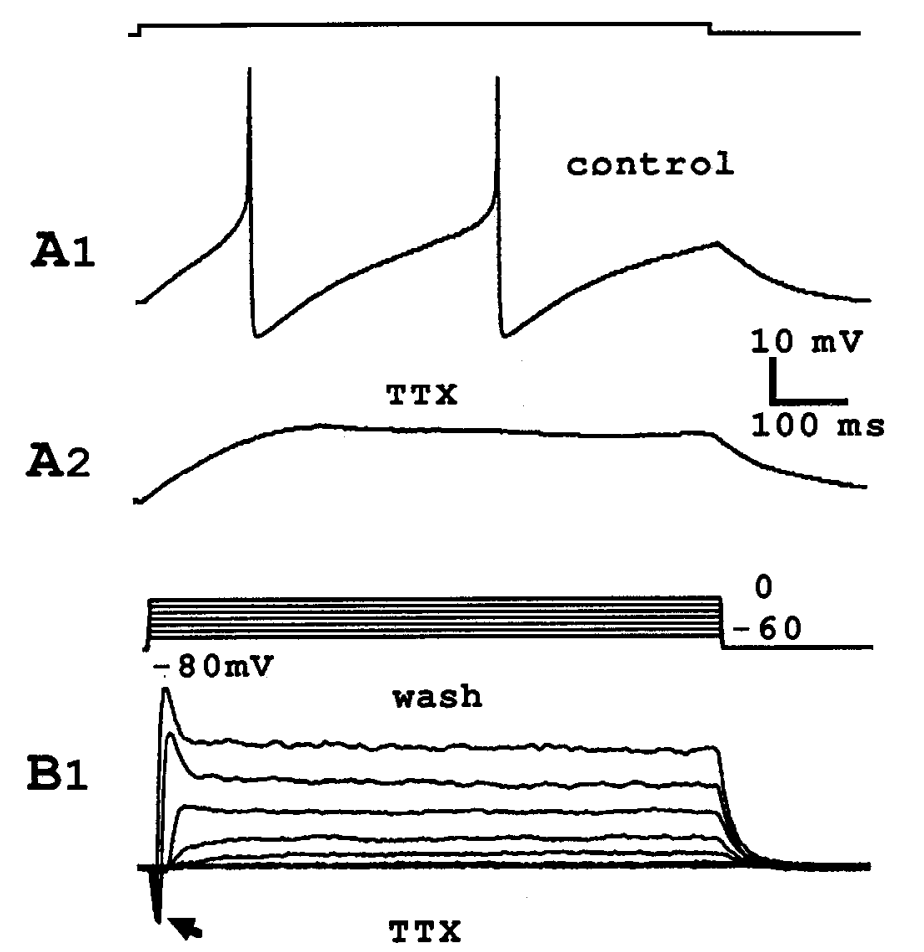

B2

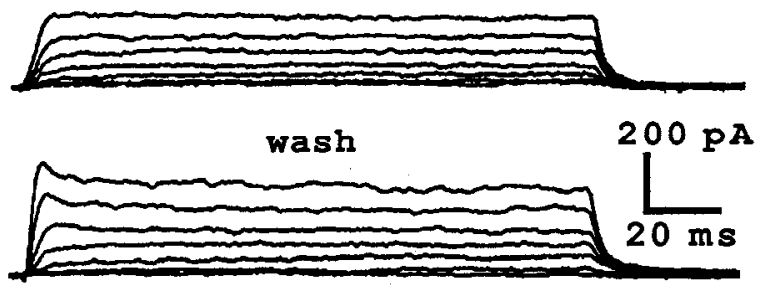

Figure 11. TTX-sensitive current. $A$, Action potentials evoked by $10-$ $\mathrm{pA}$ depolarizing current injection $\left(A_{l}\right)$ were blocked by $10^{-8} \mathrm{M}$ TTX $\left(A_{2}\right) . V_{r}=-53.7 \mathrm{mV}$ in $A_{l},-52.7 \mathrm{mV}$ in $A_{2} . B$, The same neuron was subjected to voltage-clamp study after TTX was removed by wash $\left(B_{1}\right)$. Note inward currents (arrow) preceding outward currents. Application of $10^{-8} \mathrm{M}$ TTX blocked part of the outward current as well as the inward current $\left(B_{2}\right)$. After $2 \mathrm{~min}$ wash. Note partial recovery of outward currents $\left(B_{3}\right)$.

were interested in the relative contributions of $\mathrm{Ca}^{2+}$ versus $\mathrm{Na}^{+}$ currents in generating the graded and all-or-none types of regenerative responses (Fig. $14 A_{l}, B_{l}$ ). At a concentration of $10^{-8}$ $M$, TTX blocked both all-or-none action potentials and graded regenerative potentials (Fig. $14 A_{2}, B_{2}$ ), implicating a major role of $\mathrm{Na}^{+}$currents in generating electric activity in these neurons. However, the $\mathrm{Ca}^{2+}$ current may still play a role in initiating and shaping the electrical responses even though it cannot sustain regenerative potentials by itself. The effect of the $\mathrm{Ca}^{2+}$ current on membrane depolarization was revealed by reducing $\mathrm{K}^{+}$currents. With the addition of 10-20 mM TEA to the bath solution containing TTX, graded type neurons were capable of producing slow but large voltage oscillations (Fig. $14 B_{3}$ ). These regenerative potentials were enhanced by replacing $\mathrm{Ca}^{2+}$ with $\mathrm{Ba}^{2+}$ and were blocked by $1 \mathrm{mM} \mathrm{Co}^{2+}$ in the bath solution (not shown). In contrast, all-or-none type neurons showed little or no hint of regenerative responses even with the presence of a higher concentration of TEA in the bath solution (Fig. 14 $A_{3}$ ).

The above results suggest that the contribution of $\mathrm{Ca}^{2+}$ currents is greater in the graded type than in the all-or-none type of regenerative potentials. The fact that all-or-none spikes had
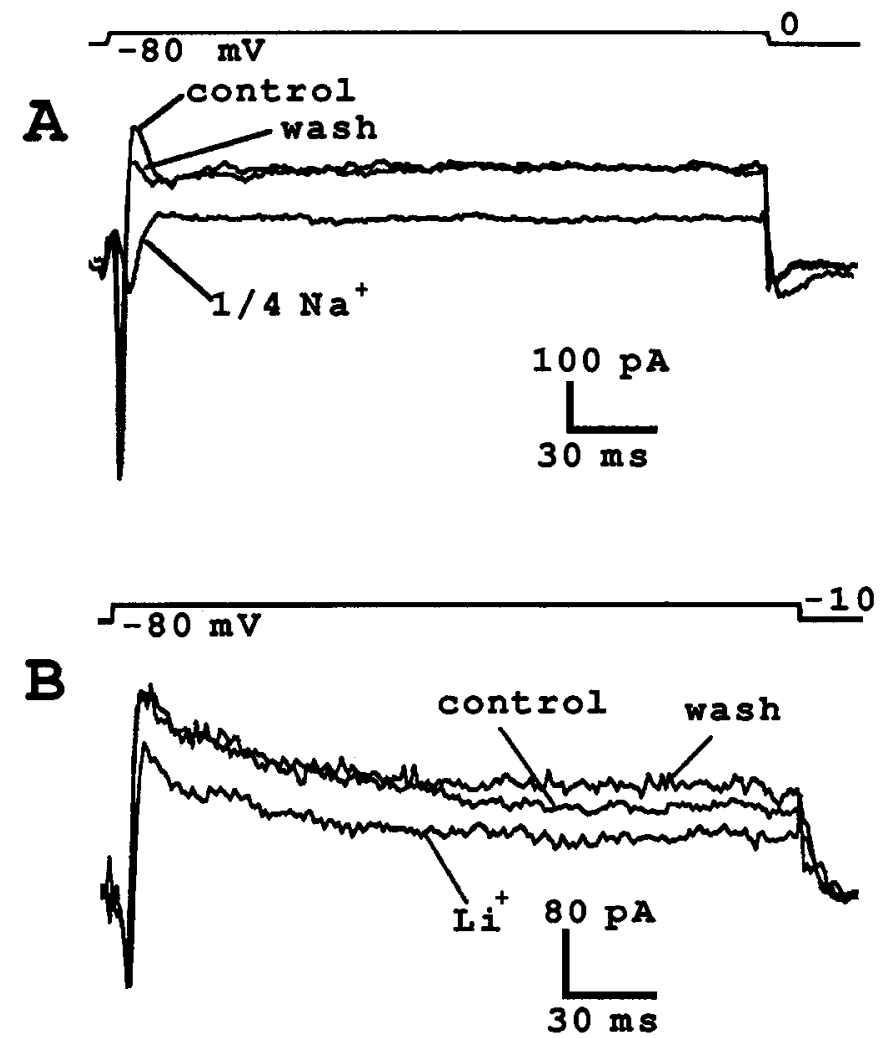

Figure 12. $\mathrm{Na}^{+}-$dependent outward current. $A$, Both inward and outward currents were reduced at a low (1/4) external $\mathrm{Na}^{+}$concentration. The remaining inward current (primarily $\mathrm{Ca}^{2+}$ current) had a slower time course. After returning to normal solution, both inward and outward currents showed partial recovery. $V_{H}=-80 \mathrm{mV}$; test pulses to 0 mV. $B$, Replacing $\mathrm{Na}^{+}$with $\mathrm{Li}^{+}$reduced $\mathrm{Na}^{+}$-dependent outward current without affecting inward current. $V_{H}=-80 \mathrm{mV}$; test pulses to -10 $\mathrm{mV}$.

a faster time course than graded potentials in these neurons is also consistent with the observations in other species that $\mathrm{Ca}^{2+}$ spikes are generally slower in time course than $\mathrm{Na}^{+}$spikes (Hagiwara and Byerly, 1981).

\section{Categories of net membrane currents}

A series of experiments was performed without the use of any channel-blocking agent to correlate the total membrane currents with the resultant regenerative responses. As already shown, the total membrane current was a mixture of inward currents and voltage-activated and cation-activated $\left(\mathrm{Ca}^{2+}\right.$ or $\left.\mathrm{Na}^{+}\right)$outward currents. In all cells studied, outward currents appeared to be the dominant component and often masked the inward current completely (Fig. 15). Voltage-clamp records of the net total current in 122 cells were classified into three categories according to their characteristic kinetic features: (1) Fast transient (36 out of 122). Following the initial inward current, a large transient outward current rose and decayed rapidly (within 10-30 msec) to a sustained plateau of outward current (Fig. 15A). The time course of this transient outward component appeared to be faster than that of the A-type current and coincided more closcly with the transient phase of $\mathrm{Ca}^{2+}$-activated $\mathrm{K}^{+}$current in some neurons (cf. Figs. 4, 5, 10). Neurons in the remaining two categories showed little net inward current. (2) Slow transient (70 out of 122). A slowly decaying outward current was prominent that followed a time course similar to that of the A-type current (Fig. $15 B$ ). (3) No transient (16 out of 122). The net current was 

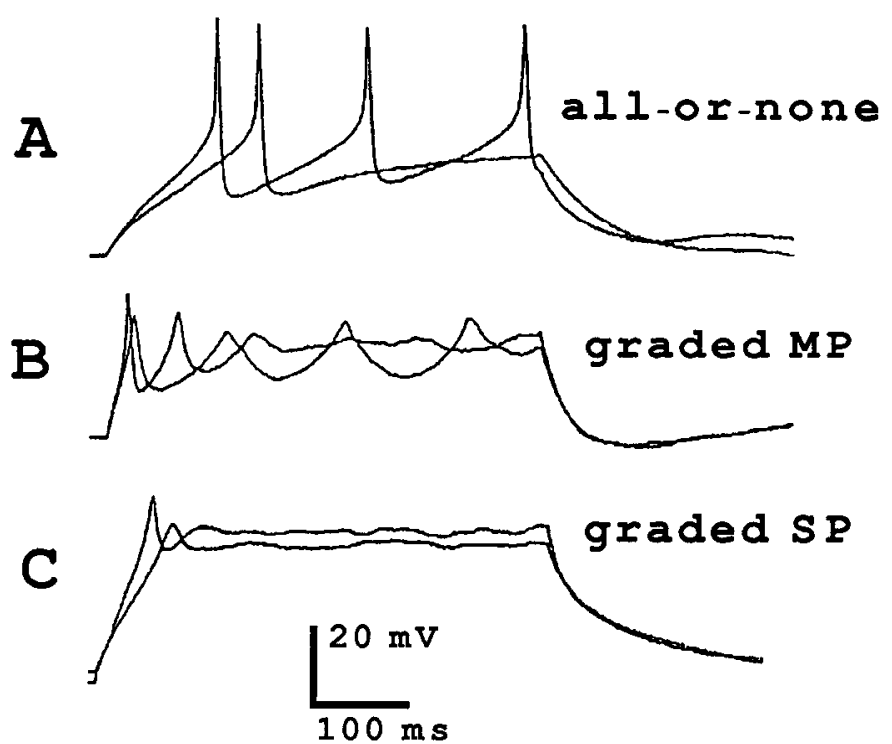

Figure 13. Types of regenerative potentials in giant neurons under current clamp. A, All-or-none; $V_{r}=-55.2$ and $55.7 \mathrm{mV}$. B, Graded, multiple-peak (graded MP); $V_{r}=-57$ and $56 \mathrm{mV}$. $C$, Graded, singlepeak (graded $S P$ ); $V_{r}=-55.7$ and $58.8 \mathrm{mV}$. Responses were induced by injecting depolarizing currents: 50 and $60 \mathrm{pA}$ in $A, 40$ and $50 \mathrm{pA}$ in $B$, and 40 and $60 \mathrm{pA}$ in $C$.

dominated by a sustained outward current that showed little decay after the initial rise. It is likely that the major outward component consisted of either the delayed rectifier or a sustained cation-activated $\mathrm{K}^{+}$current (Fig. 15C).

Different categories of current- and voltage-clamp responses observed in neurons with different numbers of primary neurites are summarized in Figure 16, $A$ and $B$. Histograms correlating voltage- and current-clamp responses collected from the same cells were also constructed (Fig. 16C). We did not find a striking correlation except the tendency that cells (16 out of 17) exhibiting a total current of the fast transient type showed regenerative potentials under current clamp (Fig. 16C) and that a higher proportion of multipolar cells showed all-or-none spikes (Fig. 16B).

We noticed that unclamped action currents were often associated with neurons displaying the slow transient-type total current and/or all-or-none action potentials. Conversely, unclamped action currents have not been seen in a total of 52 cells displaying graded or nonregenerative types of voltage responses. The above results suggest that in some all-or-none type cells the regenerative currents occurred in remote neuritic areas where membrane potentials were difficult to control by the patch electrode positioned at the soma. Under voltage clamp, fast transient-type neurons (30 out of 34) displayed clear net inward currents, which presumably induced the subsequent cation-activated $\mathrm{K}^{+}$outward currents (Fig. 15). Some of these cells were also studied under current clamp, and a majority of them (11 out of 17) showed graded-type responses. This suggests that channels mediating inward currents may be more abundant in the soma than the neurites in neurons of the fast transient category.

\section{Expression of slowpoke mutant phenotypes}

The mutation slowpoke (slo) has been shown to eliminate the transient $\mathrm{Ca}^{2+}$-activated $\mathrm{K}^{+}$current in adult and larval muscles (Elkins et al., 1986; Singh and Wu, 1989; Komatsu et al., 1990). Consequently, slo muscle fibers are more excitable, displaying broadened action potentials (Elkins and Ganetzky, 1988; Singh and $\mathrm{Wu}, 1990$ ). It is important to determine the role of the slo gene product in neurons.

Neurons in slo cultures showed all three types of voltage responses to current injection (Fig. 17A) as described above for wild-type neurons. In addition, several kinds of irregular regenerative responses not seen in wild-type neurons have been observed in a subset of slo neurons. Figure 18 shows examples of such responses, including oscillations of irregular amplitudes and tiny spikes riding on top of large, slow waves of depolarization (Fig. 18$A_{I}, A_{2}$ ), which were observed even in neurons with relatively simplc (monopolar) morphology. It was also evident that some all-or-none type neurons in slo cultures exhib-
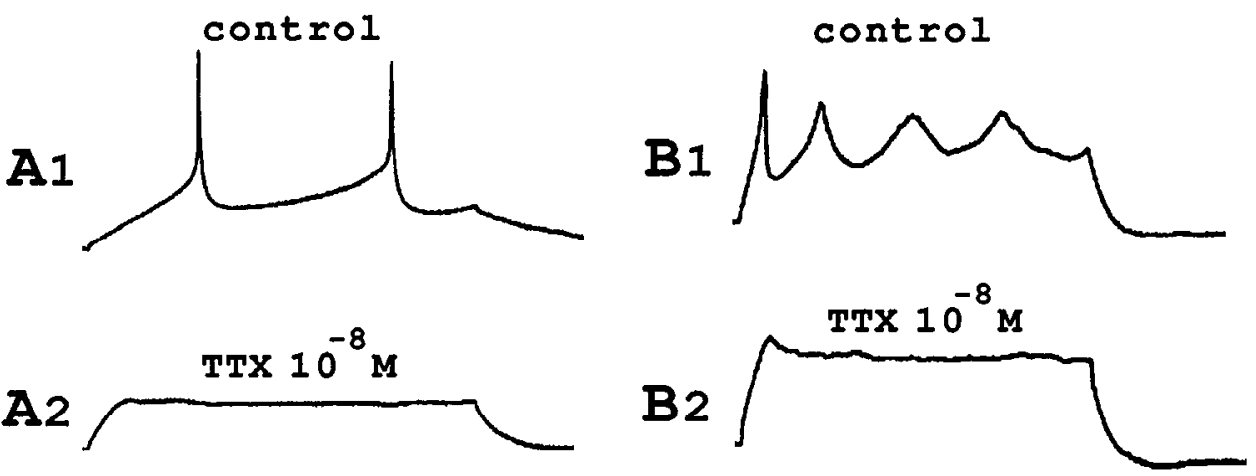

Figure 14. Effects of TTX and TEA on neurons displaying all-or-none or graded regenerative responses. $A$, Allor-none action potentials induced by 20 pA current injection $\left(A_{i} ; V_{r}=-55.7\right.$ $\mathrm{mV})$ were blocked by $10^{-8} \mathrm{M}$ TTX $\left(A_{2}\right.$; $25 \mathrm{pA} ; V_{r}=53.2 \mathrm{mV}$ ). No significant change in excitability was observed after further addition of $20 \mathrm{mM}$ TEA $\left(A_{3}\right.$; $\left.34 \mathrm{pA} ; V_{r}=56.6 \mathrm{mV}\right)$. $B$, Graded regenerative potentials $\left(B_{i} ; V_{r}=-57.6\right.$ $\mathrm{mV}$ ) were suppressed by $10^{-8} \mathrm{M}$ TTX $\left(B_{2} ; V_{r}=-62 \mathrm{mV}\right)$. Large membrane oscillations could be induced following further addition of $20 \mathrm{mM}$ TEA $\left(B_{3} ; V_{r}\right.$ $=-59.6 \mathrm{mV})$. All cells received $40-\mathrm{pA}$ injection.
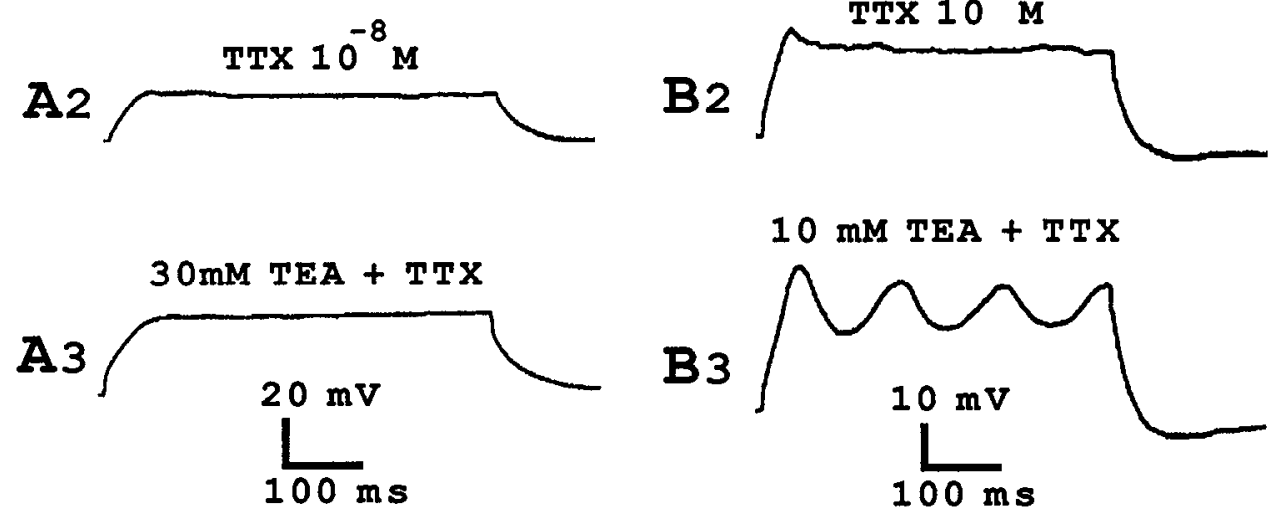


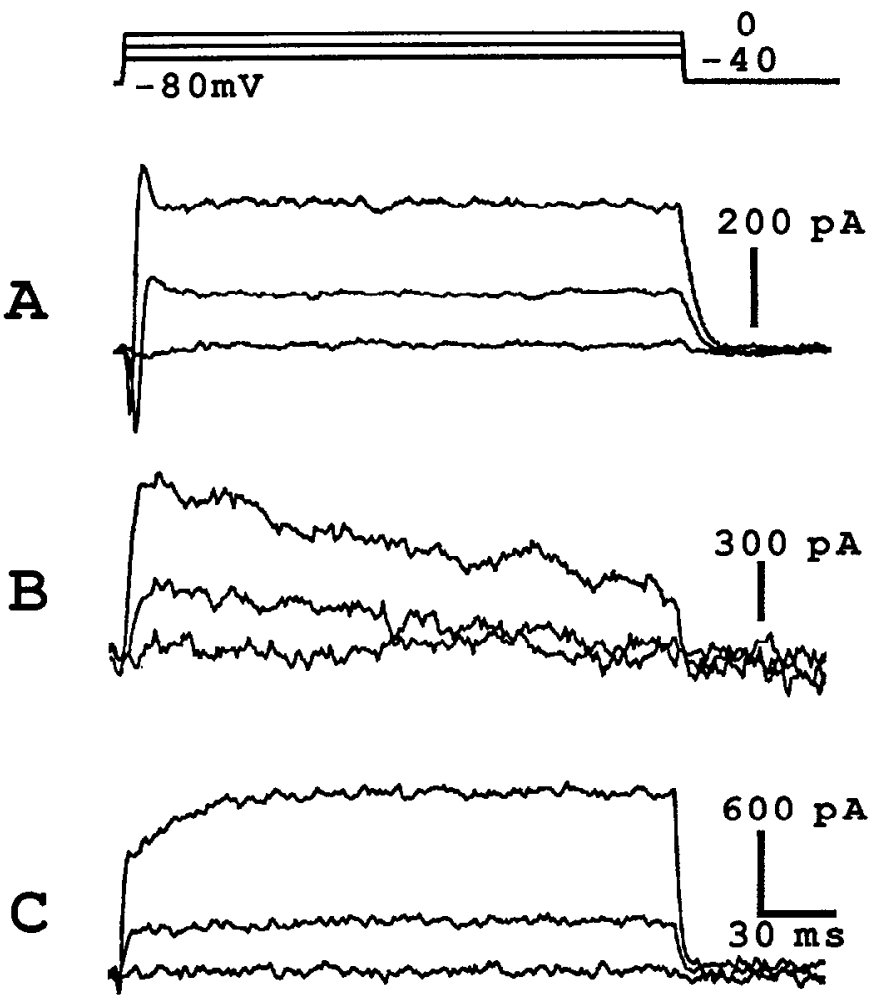

Figure 15. Categories of total membrane currents according to kinetics of the net outward currents under voltage-clamp conditions. $A$, Fast transient. $B$, Slow transient. $C$, No transient. $V_{H}=-80 \mathrm{mV}$; test pulses to $-40,-20$, and $0 \mathrm{mV}$.

ited regenerative potentials of an increased duration. Such effect was variable, ranging from no apparent change to about a fourfold lengthening in action-potential duration (Fig. $18 B_{1}, B_{2}$ ). Variation in action-potential broadening may reflect differences in the relative contributions between voltage-activated and $\mathrm{Ca}^{2+}$ activated $\mathrm{K}^{+}$currents to membrane repolarization. This notion is supported by the following observations.

In slo neurons that displayed relatively normal spikes, partial inactivation of the A-type current by membrane depolarization $(-45 \mathrm{mV})$ broadened action potentials and shortened the delay to their initiation (Fig. 19). In wild-type neurons, only decrease in onset time but not spike broadening was induced by subthreshold membrane depolarization (Fig. 19; see also Fig. 3). Prolonged current injection further inactivated the A-type current and tended to increase the duration of action potentials in slo but not in wild-type neurons (Fig. $18 B_{2}, B_{3}$ ). The above results are consistent with a reduction of $\mathrm{Ca}^{2+}$-activated $\mathrm{K}^{+}$current in slo neurons. Repolarization of neuronal action potentials thus appears to depend on both $\mathrm{Ca}^{2+}$-activated and voltage-activated $\mathrm{K}^{+}$currents, and the effect of slo became more evident when the A-type current was inactivated.

Voltage-clamp experiments employing the paradigm shown in Figure 10 suggested that, compared to wild-type neurons, a lower percentage of slo neurons had $\mathrm{Ca}^{2+}$-activated outward $\mathrm{K}^{+}$ current. The differences between membrane currents before and after addition of $\mathrm{Co}^{2+}$ to saline (containing $10^{-8} \mathrm{M}$ TTX) were determined. In 6 out of 16 slo neurons examined, the net $\mathrm{Co}^{2+}$. sensitive current was purely inward, whereas only 3 out of 18 wild-type neurons displayed a purely inward net current (Figs. $10 F, G ; 17 B)$. The remaining 10 slo and 15 wild-type neurons
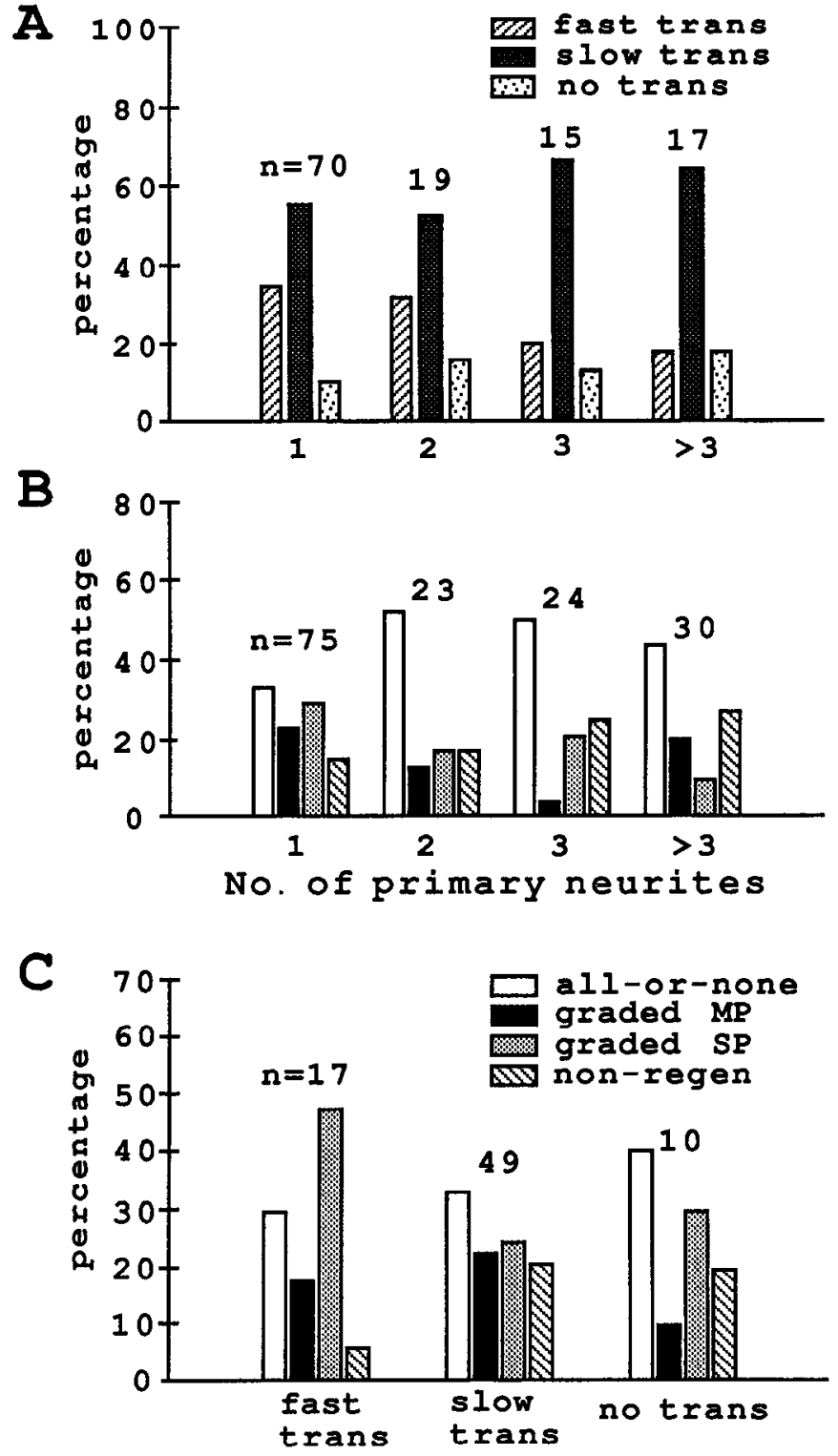

Figure 16. Summary of current- and voltage-clamp data collected from neurons with different morphology. $A$, Correlation between number of primary neurites and types of voltage-clamp responses. $B$, Correlation between number of primary neurites and types of current-clamp responses. C, Correlation of current- and voltage-clamp data collected from the same neuron. See Figures 13 and 15 for categories of currentand voltage-clamp responses.

showed outward net current. However, the outward component in these slo neurons was significantly reduced $(3.43 \pm 3.39 \mathrm{pA} /$ $\mathrm{pF}$, mean $\pm \mathrm{SD}$, as compared with $8.12 \pm 7.61 \mathrm{pA} / \mathrm{pF}$ in wildtype neurons at the transient peak evoked by a depolarizing step to $20 \mathrm{mV}$ ). Although not all wild-type neurons express $\mathrm{Ca}^{2+}$. activated current uniformly (Fig. 10D-F), the above results do suggest that slo affects the $\mathrm{Ca}^{2+}$-activated current at least in a subpopulation of neurons, in which both the transient and sustained components of the $\mathrm{Ca}^{2+}$-activated current were either eliminated or significantly reduced.

It is interesting to note that the action-potential broadening by the slo mutation appeared to be more pronounced in the neurites. In two successful attempts to perform recordings from neurites, successive action potentials induced by sustained cur- 
A

$$
\begin{gathered}
\text { Current-clamp } \\
\text { all-or-none } \\
\text { graded MP } \\
\text { graded } S P \\
\text { non-regen } \\
\text { irregular }
\end{gathered}
$$

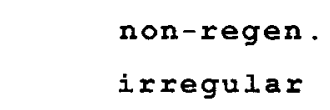

voltage-clamp studies from slo neurons in comparison with wild-type data. $A$, Distributions of different types of responses observed under current clamp in wild-type and slo neurons. Note the absence of the irregular type of response in wild-type neurons. $B$, Percentage of neurons exhibiting purely inward $\mathrm{Co}^{2+}$ sensitive currents under voltage clamp. Note a higher proportion of such neurons in slo culture. $M P$, multiple peak; $S P$, single peaks.
B

Voltage-clamp
purely inward

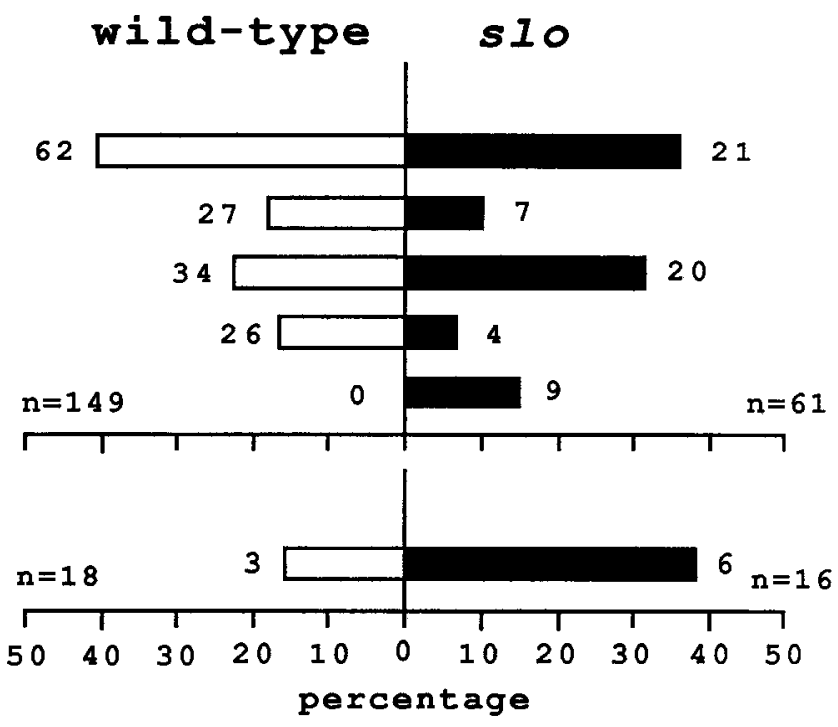

In primary cultures derived from Drosophila whole embryos and larval CNS, a major difficulty in studying mutational effects on neurons is the small cell size compounded with inhomogeneity in membrane currents expressed in different cell types. Previous studies of mutant effects relied on statistical analysis of large samples (O'Dowd and Aldrich, 1988; Baker and Salkoff, 1990). We found it possible to correlate current- and voltageclamp records from the same giant neuron in cytochalasin Btreated cultures, which has not yet been achieved in untreated ncurons. This approach cnables us to determine, within individual neurons, the role of various currents in the generation of action potentials and regulation of membrane excitability, circumventing some of the problems imposed by cellular inhomogeneity. As the experiments on slo giant neurons demonstrated, current-clamp analysis may provide a sensitive screening method to detect the range of mutational effects on membrane excitability in different neurons and to determine the alterations in the corresponding currents.

\section{Inward $\mathrm{Na}^{+}$and $\mathrm{Ca}^{2+}$ currents}

By using $\mathrm{Na}^{+}$-free solution or applying TTX, we isolated the $\mathrm{Ca}^{2+}$ inward current that was sensitive to inorganic blockers such as $\mathrm{Co}^{2+}, \mathrm{Cd}^{2+}$, and $\mathrm{La}^{3+}$. Giant neurons producing graded regenerative potentials appear to show greater $\mathrm{Ca}^{2+}$-dependent depolarizations than those displaying all-or-none action potentials (Fig. 14). In voltage-clamp experiments, some neurons showed exclusively inactivating $\mathrm{Ca}^{2+}$ currents, while the others displayed a substantial noninactivating component (Fig. 9), suggesting the possibility of $\mathrm{Ca}^{2+}$ channel subtypes. The existence of two different $\mathrm{Ca}^{2+}$ channels in Drosophila embryonic neurons has been recently demonstrated by using spider toxins (Leung et al., 1989). It will be important to determine the roles of $\mathrm{Ca}^{2+}$ currents with different inactivation kinetics in shaping the regenerative response.

Inward $\mathrm{Na}^{+}$current isolated by replacing $\mathrm{Ca}^{2+}$ with $\mathrm{Co}^{2+}$ showed voltage dependence similar to the $\mathrm{Na}^{+}$current in cultured embryonic neurons (O'Dowd and Aldrich, 1988). More than $50 \%$ of the neurons generated a transient inward $\mathrm{Na}^{+}$current with a delay of a few milliseconds following the voltage steps. The delay decreased as depolarization increased, indicating that the main source of the $\mathrm{Na}^{+}$current was localized in locust (Burrows, 1979; Goodman and Heitler, 1979; Laurent, 1990). 

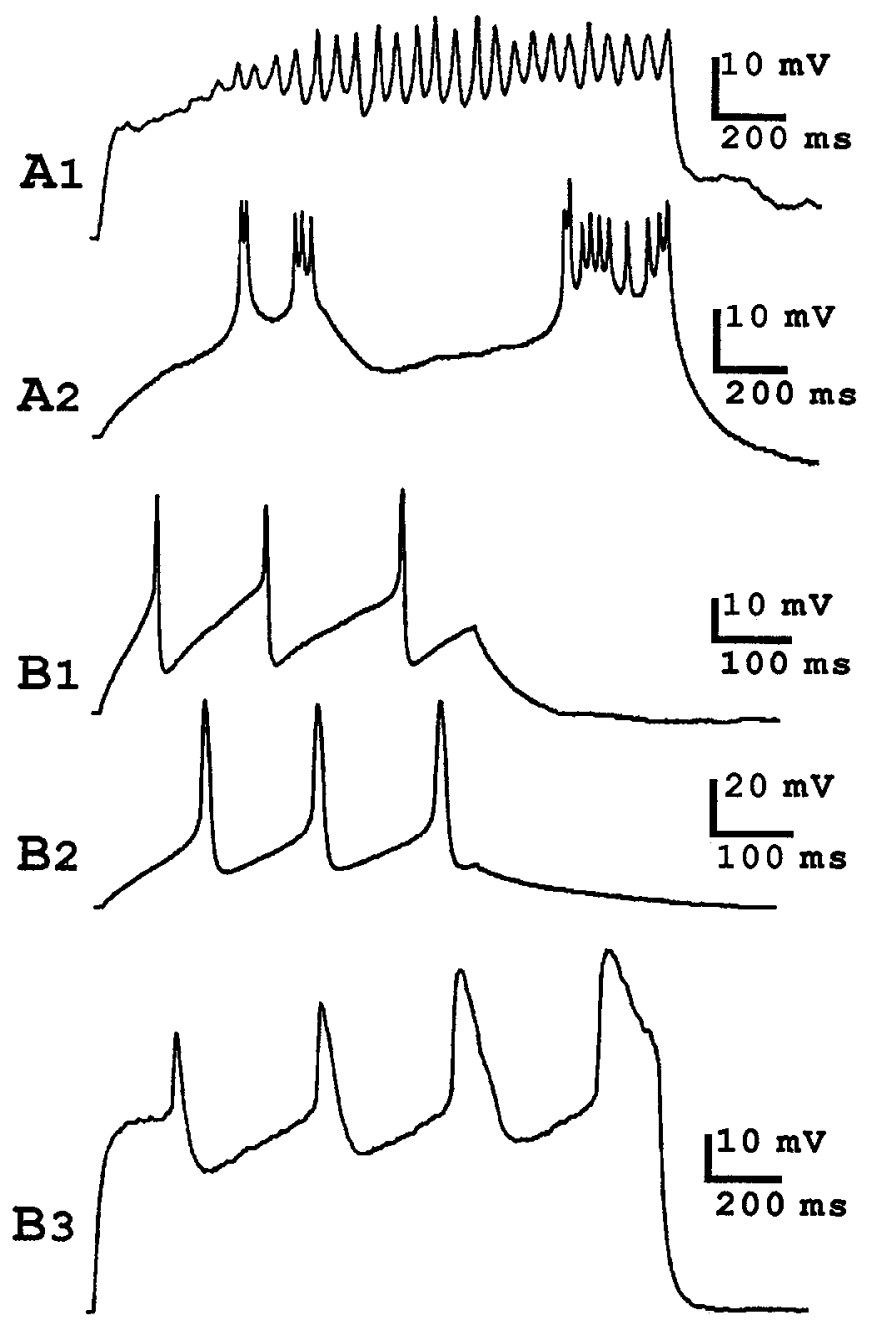

Figure 18. Abnormal regenerative responses in slo neurons under current clamp. $A$, Examples of irregular regenerative potentials from two slo neurons not seen in wild-type neurons $\left(A_{i}: V_{r}=-61.5 \mathrm{mV} ; 40 \mathrm{pA}\right.$ injection; $A_{2}: V_{r}=-49.8 \mathrm{mV} ; 10 \mathrm{pA}$ ). $B$, All-or-none responses in different neurons showed variable degrees of abnormality. $B_{l}$, Action potentials with similar durations seen in wild-type neurons. $V_{r}=-56$ $\mathrm{mV} ; 50 \mathrm{pA} . B_{2}$, Action potentials with durations significantly longer than that of wild-type neurons. $V_{r}=-53 \mathrm{mV} ; 18 \mathrm{pA} . B_{3}$, Action potentials recorded from neurites that showed progressive broadening in their duration. $V_{r}=-64.0 \mathrm{mV} ; 80 \mathrm{pA}$.

neurites where voltage was not satisfactorily controlled. Similar observations regarding $\mathrm{Na}^{+}$channel distribution have also been reported in cultured embryonic neurons in culture (O'Dowd and Aldrich, 1988). In contrast, we did not encounter such difficulty in voltage-clamp measurements of $\mathrm{Ca}^{2+}$ currents. This difference suggests that the soma expresses a higher density of $\mathrm{Ca}^{2+}$ channels, whereas $\mathrm{Na}^{+}$channels are more abundant in neurites.

About $70 \%$ of giant neurons expressing inward $\mathrm{Na}^{+}$current showed a persistent component (Fig. 8B). The transient and persistent components showed marked differences in steadystate inactivation but were both blocked by TTX and depended on external Na+ ${ }^{+}$(Fig. 8B,C). Persistent $\mathrm{Na}^{+}$currents (or conductances) have been reported in neurons of insects (Yawo et al., 1985; Christensen et al., 1988; Lapied et al., 1989), crustaceans (Davis and Stuart, 1988), and mammals (Stafstrom et al., 1985; Rekling and Laursen, 1989; French et al., 1990). Molecular studies have shown that small subunits (e.g., $\beta$-subunit)

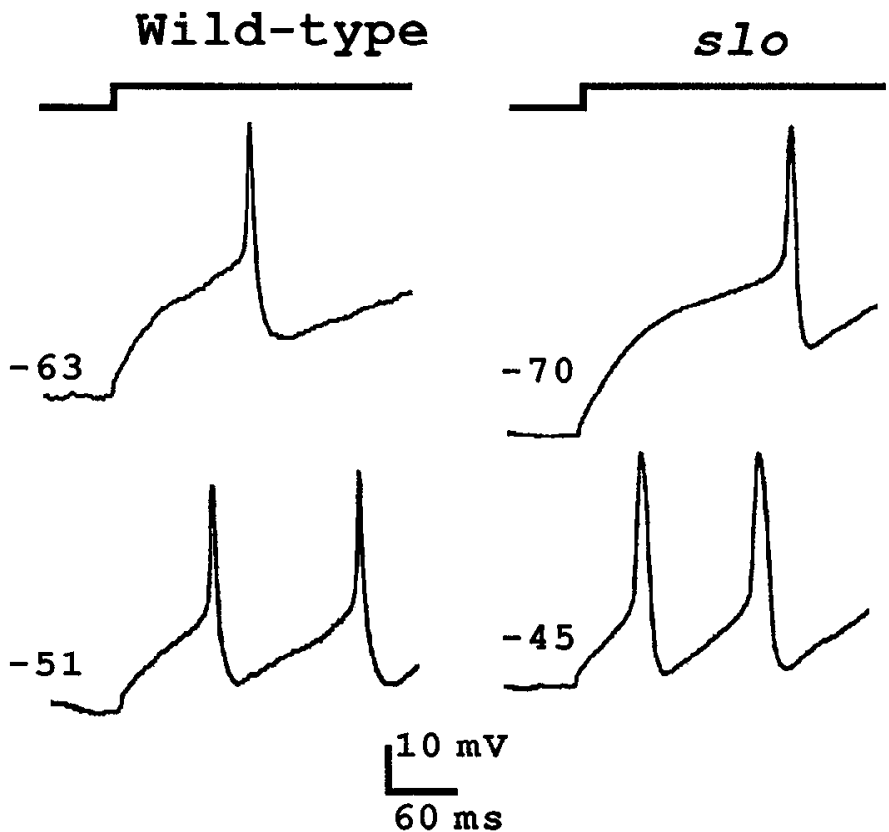

Figure 19. Effects of the resting membrane potential on action-potential broadening in a wild-type and a slo neuron. The membrane potential was set at different values as indicated. Inactivation of the A-type current by membrane depolarization shortened the delay in action-potential onset in both wild-type and slo neurons. This also prolonged the action potentials in slo but not wild-type neurons. The amplitudes of the current pulses in these sequential recordings were 20 and $13 \mathrm{pA}$ in the wild-type and 40 and $30 \mathrm{pA}$ in the slo neuron.

may contribute to the regulation of $\mathrm{Na}^{+}$channel inactivation (Auld et al., 1988; Krafte et al., 1988). In addition, there may be multiple types of the $\alpha$-subunit that coexist in neurons. In fact, more than one gene in Drosophila have been implicated to code for $\mathrm{Na}^{+}$channels (Okamoto et al., 1987; Salkoff et al., 1987; Loughney et al., 1989; Ramaswami and Tanouye, 1989) or to affect $\mathrm{Na}^{+}$channel function (Ganetzky, 1986; Jackson ct al., 1986; O'Dowd and Aldrich, 1988). In particular, the para gene may produce multiple types of $\mathrm{Na}^{+}$-channel $\alpha$-subunit by an alternative splicing mechanism (Loughney et al., 1989). It will be of interest to determine whether or not the two components reported here represent two $\mathrm{Na}^{+}$channel populations in Drosophila.

\section{Voltage-activated $\mathrm{K}^{+}$outward currents}

Previous studies in Drosophila muscle fibers (Salkoff and Wyman, 1983; Wu and Haughland, 1985; Haugland and Wu, 1990) and dissociated neurons (Byerly and Leung, 1988; Solc and Aldrich, 1988) demonstrated two different types of voltage-activated $\mathrm{K}^{+}$currents, which can be separated on the basis of pharmacological or physiological differences. Our results from giant neurons indicate that the same two currents, the 4-APsensitive, inactivating, A-type current and the delayed rectifier, could be isolated in the presence of $\mathrm{Na}^{+}$and $\mathrm{Ca}^{2+}$ channel blockers (Figs. 4-6). Current-clamp experiments suggested that the A-type current appeared to be involved in regulating actionpotential initiation, repolarization, and repetitive firing in the giant neuron. Partial inactivation of the channels by depolarizing holding currents led to more rapid action-potential initiation (Fig. 3) and higher firing frequencies (M. Saito and C.-F. $\mathrm{Wu}$, unpublished observations). In the case of larval motor axon 
terminals, it has been reported that removal of the current by 4-AP or Shaker mutations prolongs transmitter release because of prolonged action potentials and repetitive firing at the terminal. This phenotype becomes more extreme at reduced $\mathrm{Ca}^{2+}$ concentrations, probably due to a more important role of the A-type current in membrane repolarization when the $\mathrm{Ca}^{2+}$-activated $\mathrm{K}^{+}$current is weakened at lower $\mathrm{Ca}^{2+}$ levels (Jan et al., 1977; Ganetzky and Wu, 1982, 1983; Mallart et al., 1991). In adult cervical giant fibers, blockade or modifications of the A-type channels by Shaker mutations also results in prolonged action potential and, in some case, repetitive firing (Tanouye et al., 1981; Tanouye and Ferrus, 1985).

Our data suggest that A-type channels have nonuniform voltage dependence and inactivation kinetics (Fig. 5). Some variation might be derived from factors affecting voltage-clamp measurements, for example, differences in the proportions among cell input resistance, seal resistance, and series resistance (see Materials and Methods). A more detailed study in the soma of dissociated pupal thoracic neurons has also revealed significant variation in inactivation properties of the A-type current and the coexistence of two populations of channels in some cells (Baker and Salkoff, 1990). It is possible that the A-type channels inactivating at more negative potentials may be involved in the delay of action-potential initiation and regulation of firing rate (Connor and Stevens, 1971; Getting, 1983; Hille, 1984), whereas those inactivating at more positive potentials may be more important to action-potential repolarization.

\section{$T T X$-sensitive $K^{+}$current}

$\mathrm{Na}^{+}$-activated $\mathrm{K}^{+}$currents have been observed in whole-cell voltage-clamp studies as a transient outward current following the $\mathrm{Na}^{+}$inward current in chick neurons (Bader et al., 1985; Dryer et al:, 1989) and crayfish motor neurons (Hartung, 1985). This type of channel appears to be activated by $\mathrm{Na}^{+}$influx through the voltage-gated $\mathrm{Na}^{+}$channel. In cell-free patches, the channel activity is proportional to the $\mathrm{Na}^{+}$concentration on the cyloplasmic side without signs of inactivation (Kameyama et al., 1984; Haimann et al., 1990). The following lines of evidence suggest the presence of a similar $\mathrm{Na}^{+}$-activated $\mathrm{K}^{+}$channel in Drosophila giant neurons: First, TTX not only blocked the inward current, but also significantly decreased the outward current. Second, in $\mathrm{Na}^{+}$-free saline, the outward current was also reversibly reduced (Fig. 12A). Third, substitution of $\mathrm{Na}^{+}$with $\mathrm{Li}^{+}$in bath left the inward current intact but reduced the outward current (Fig. 12B). Apparently, $\mathrm{Li}^{+}$could pass though $\mathrm{Na}^{+}$channcls but failed to activate this TTX-sensitive $\mathrm{K}^{+}$current (see Bader et al., 1985; Dryer et al., 1989). Finally, the major charge carrier for this current is most likely to be $\mathrm{K}^{+}$for the following reasons: This outward current was blocked by internal $\mathrm{Cs}^{+}$(cf. Fig. 8), and its tails reversed at about $-80 \mathrm{mV}$ (data not shown), which was close to the Nernst potential for the $\mathrm{K}^{+}$gradient (2 $\mathrm{mm} / 144 \mathrm{~mm}$ ). In different cells, the amount of $\mathrm{Na}^{+}$-activated outward current varied in terms of the absolute and relative amplitude of the transient and sustained components, which may reflect activation by the transient and persistent components of $\mathrm{Na}^{+}$current. It will be important to investigate interactions between the $\mathrm{Na}^{+}$current and the $\mathrm{Na}^{+}$-activated $\mathrm{K}^{+}$current. Regulation of these two currents, analogous to the interplays between the $\mathrm{Ca}^{2+}$ and $\mathrm{Ca}^{2+}$-activated $\mathrm{K}^{+}$currents, may provide neurons with additional handles to enrich their signaling capability.

\section{$\mathrm{Ca}^{2+}$-activated $\mathrm{K}^{+}$currents and effects of the slo mutation}

The transient and the sustained components of $\mathrm{Ca}^{2+}$-activated $\mathrm{K}^{+}$currents have been described in Drosophila adult and larval muscles (Salkoff, 1983; Wei and Salkoff, 1986; Gho and Mallart, 1986). These two components represent two distinct channel populations because slo eliminates the transient component $\left(I_{C F}\right)$ but not the sustained component $\left(I_{\mathrm{CS}}\right)$ of $\mathrm{Ca}^{2+}$-activated $\mathrm{K}^{+}$currents (Elkins et al., 1986; Singh and Wu, 1989, 1990). In addition, current components similar to these two have been observed in a variety of neurons in other species (Meech, 1974; Blatz and Magleby, 1987; Rudy, 1988; Latorre et al., 1989). A noninactivating $\mathrm{Ca}^{2+}$-activated $\mathrm{K}^{+}$current has been reported in Drosophila embryonic neurons in culture (Byerly and Leung, 1988). Our study indicates that a transient $\mathrm{Ca}^{2+}$-activated $\mathrm{K}^{+}$ current is likely to be present in Drosophila neurons, as well (Fig. 10).

The $\mathrm{Co}^{2+}$-sensitive outward component was clearly reduced in slo giant neurons. However, the expression of $\mathrm{Ca}^{2+}$-activated transient $\mathrm{K}^{+}$current does not appear uniform (Fig. 10D-F), and the slo mutation did not eliminate all $\mathrm{Co}^{2+}$-sensitive outward components in at least a subset of neurons (Fig. 17B). In addition, slo appears to affect the late component as well as the early peak of the $\mathrm{Co}^{2+}$-sensitive outward current, contrasting to the selective elimination of the transient $\mathrm{Ca}^{2+}$-activated $\mathrm{K}^{+}$current in muscle. Recent DNA sequence analysis indicates that the slo gene codes for a channel polypeptide (Robertson et al., 1991). However, a previous study demonstrates a lack of clear gene-dosage effect of the slo mutations (Komatsu et al., 1990), raising the possibility that the $\mathrm{Ca}^{2+}$-activated $\mathrm{K}^{+}$channel may contain additional subunits from different genes. Therefore, discrepancies in slo effects on nerve and muscle could be explained by the slo gene product being utilized differently in neurons and muscle cells.

Current-injection experiments suggest that, in cells generating all-or-none action potentials, slo prolonged the action potential, especially when the A-type current was inactivated (Fig. 19). Similar conclusions have been drawn from previous intracellular recordings in adult (Elkins et al., 1986) and larval (Singh and $\mathrm{Wu}, 1990$ ) muscles of slo mutants. Complex regenerative activity was observed in some slo giant neurons (Fig. 18A), suggesting that the lack of $\mathrm{Ca}^{2+}$-activated $\mathrm{K}^{+}$current may result in distinct activity patterns under different circumstances. In principle, differential distribution of membrane channels mediating various inward and outward currents in different subcellular regions can give rise to complex electric interactions. It will be interesting to determine whether the channels affected by slo have a nonuniform distribution (e.g., neurites vs. somata, as suggested by Fig. $18 B_{3}$ ).

The present study indicates that this giant neuron system is suitable for physiological, pharmacological, and cell biological analyses. Further studies of slo and additional mutants using giant neurons may provide insights into mechanisms of channels and relatcd protcins, their expression in subcellular regions, and their roles in determining membrane excitability.

\section{References}

Armstrong CM, Bezanilla F (1973) Currents related to movement of the gating particles of the sodium channels. Science 242:459-461.

Auld VJ, Goldin AL, Krafte DS, Marshall J, Dunn JM, Catterall WA, Lester HA, Davidson N, Dunn RJ (1988) A rat $\mathrm{Na}^{+}$channel $\alpha$ subunit with novel gating properties. Neuron 1:449-461. 
Bader CR, Bernheim L, Bertrand D (1985) Sodium-activated potassium current in cultured avian neurons. Nature 317:540-542.

Baker K, Salkoff L (1990) The Drosophila Shaker gene codes for a distinctive $\mathrm{K}^{+}$current in a subset of neurons. Neuron 2:129-140.

Blatz AL, Magleby KL (1987) Calcium-activated potassium channels. Trends Neurosci 10:463-467.

Burrows M (1979) Synaptic potentials effect the release of transmitter from locust nonspiking interneurons. Science 204:81-83.

Byerly L, Leung H-T (1988) Ionic currents of Drosophila neurons in embryonic cultures. J Neurosci 8:4379-4393.

Christensen BN, Larmet Y, Shimahara T, Beadle D, Pichon Y (1988) Ionic currents in neurones cultured from embryonic cockroach (Periplaneta americana) brains. J Exp Biol 135:193-214.

Connor JA, Stevens CF (1971) Voltage clamp studies of a transient outward membrane current in gastropod neuronal somata. J Physiol (Lond) 213:21-30.

Davis RE, Stuart AE (1988) A persistent, TTX-sensitive sodium current in an invertebrate neuron with neurosecretory ultrastructure. $J$ Neuroscience 8:3978-3991.

Dryer SE, Fujii J, Martin ARA (1989) $\mathrm{Na}^{+}$-activated $\mathrm{K}^{+}$current in cultured brain stem neurones from chicks. J Physiol (Lond) 410:283296.

Elkins T, Ganetzky B (1988) The role of potassium currents in Drosophila flight muscles. J Neurosci 8:428-434.

Elkins T, Ganetzky B, Wu C-F (1986) A Drosophila mutation that eliminate a $\mathrm{Ca}^{2+}$-dependent $\mathrm{K}^{+}$current. Proc Natl Acad Sci USA 83: 8415-8419.

French CR, Sah P, Buckelt KJ, Gage PW (1990) A voltage-dependent persistent sodium current in mammalian hippocampal neurons. J Gen Physiol 95:1139-1157.

Ganetzky B (1986) Neurogenic analysis of Drosophila mutations affecting sodium channels: synergistic effects on viability and nerve conduction in double mutations involving tip-E. J Neurogenet 3:1931.

Ganetzky B, Wu C-F (1982) Drosophila mutants with opposing effects on nerve excitability: genetic and spatial interactions in repetitive firing. J Neurophysiol 47:501-514.

Ganetzky B, Wu C-F (1983) Neurogenetic analysis of potassium currents in Drosophila: synergistic effects on neuromuscular transmission in double mutants. J Neurogenet 1:17-28.

Ganetzky B, Wu C-F (1986) Neurogenetics of membrane excitability in Drosophila. Annu Rev Genet 20:13-44.

Getting PA (1983) Mechanisms of pattern generation underlying swimming in Tritonia. III. Intrinsic and synaptic mechanisms for delayed excitation. J Neurophysiol 49:1036-1050.

Gho M, Mallart A (1986) Two distinct $\mathrm{Ca}^{2+}$-activated $\mathrm{K}^{+}$currents in larval muscle fibers of Drosophila melanogaster. Pfluegers Arch 407: $526-533$.

Goodman CS, Heitler WJ (1979) Electrical properties of insect neurones with spiking and nonspiking somata: normal, axotomised, and colchicine-treated neurones. J Exp Biol 83:95-121.

Hagiwara S, Byerly L (1981) Calcium channel. Annu Rev Neurosci 4:69-125.

Hagiwara S, Watanabe A (1956) Discharges in motoneurons of Cicada. J Cell Comp 47:415-428.

Haimann C, Bernheim L, Bertraund D, Bader CR (1990) Potassium current activated by intracellular sodium in quail trigeminal ganglion neurons. J Gen Physiol 95:961-979.

Hall JC (1982) Genetics of nervous system in Drosophila. Q R Biophys $15: 223-479$.

Hartung K (1985) Potentiation of a transient outward current by $\mathrm{Na}^{+}$ influx in crayfish neurones. Pfluegers Arch 404:41-44.

Haugland FN, Wu C-F (1990) A voltage-clamp analysis of gene-dosage effects of the Shaker locus on larva muscle potassium currents in Drosophila. J Neurosci 10:1357-1371.

Hille B (1984) Ionic channels of excitable membranes. Sunderland, MA: Sinauer.

Huff R, Furst A, Mahowald A (1989) Drosophila embryonic neuroblasts in culture: autonomous differentiation of specific neurotransmitters. Dev Biol 134:146-157.

Ikeda K, Kaplan WD (1970) Patterned neuronal activity of a mutant Drosophila melanogaster. Proc Natl Acad Sci USA 66:765-772.

Jackson FR, Wilson SD, Hall LM (1986) The tip-E mutations of Drosophila decreases saxitoxin binding and interacts with other mutations affecting nerve membrane excitability. J Neurogenet 3:1-17.

Jan L, Jan Y (1982) Antibodies to horseradish peroxidase as specific neuronal markers in Drosophila and grasshopper embryos. Proc Natl Acad Sci USA 79:2700-2704.

Jan YN, Jan LY, Dennis MJ (1977) Two mutations of synaptic transmission in Drosophila. Proc R Soc Lond [Biol] 198:87-108.

Kameyama M, Kakei M, Sato R, Shibasaki T, Matsuda H, Irisawa $H$ (1984) Intracellular $\mathrm{Na}^{+}$activates a $\mathrm{K}^{+}$channel in mammalian cardiac cells. Nature 309:354-356.

Komatsu A, Singh S, Rathe P, Wu C-F (1990) Mutational and genedosage analysis of $\mathrm{Ca}^{2+}$-activated $\mathrm{K}^{+}$channels in Drosophila. Neuron 4:313-321.

Krafte D, Snutch TP, Leonard JP, Davidson N, Lester HA (1988) Evidence for the involvement of more than one mRNA species in controlling the inactivation process of rat and rabbit brain $\mathrm{Na}$ channels expressed in Xenopus oocytes. J Neurosci 8:2859-2868.

Lapied B, Molecot O, Pelhate M (1989) Ionic species involved in the electrical activity of single adult aminergic neurons isolated from the sixth abdominal ganglion of the cockroach Periplaneta americana. J Exp Biol 144:535-549.

Latorre R, Oberhauser A, Labarca P, Alvarez O (1989) Varieties of calcium-activated potassium channels. Annu Rev Physiol 51:385399.

Laurent G (1990) Voltage-dependent nonlinearities in the membrane of locust nonspiking local interneurons, and their significance for synaptic integration. J Neurosci 10:2268-2280.

Leung H-T, Branton WD, Philips HS, Jan L, Byerly L (1989) Spider toxins selectively block $\mathrm{Ca}^{2+}$ current in Drosophila. Neuron 3:767772.

Loughney K, Kreber R, Ganetzky B (1989) Molecular analysis of the para locus, a sodium channel gene in Drosophila. Cell 58:1 143-1154.

Mallart A, Augaut-Petit D, Bourret-Poulain C, Ferrus A (1991) Nerve terminal excitability and neuromuscular transmission in $T(X ; Y) V 7$ and Shaker mutants of Drosophila melanogaster. J Neurogenet 7:7584.

Meech RW (1974) The sensitivity of Helix aspersa neurones to injected calcium ions. J Physiol (Lond) 237:259-277.

Narahashi T, Moore JW, Scott WR (1964) Tetrodotoxin blockage of sodium conductance increase in lobster giant axons. J Gen Physiol 47:965-974.

O'Dowd DK, Aldrich RW (1988) Voltage-clamp analysis of sodium channels in wild-type and mutant Drosophila neurons. J Neurosci 8: 3633-3643.

O'Dowd DK, Germeraad SE, Aldrich RW (1989) Alterations in the expression and gating of Drosophila sodium channels by mutations in the para gene. Neuron 2:1301-1311.

Okamoto H, Sakai K, Gotto S, Tkasu-Ishikawa E, Hotta Y (1987) Isolation of Drosophila genomic clones homologous to the eel'sodium channel gene. Proc Jpn Acad 63B:284-288.

Papazian DM, Schwarz TL, Tempel BL, Timpe LC, Jan LY (1988) Ion channels in Drosophila. Annu Rev Physiol 50:379-394.

Ramaswami M, Tanouye MA (1989) Two sodium channel genes in Drosophila: implications for channel diversity. Proc Natl Acad Sci USA 86:2079-2082.

Rekling JC, Laursen AM (1989) Evidence for a persistent sodium conductance in neurons from the nucleus prepositus hypoglossi. Brain Res 500:276-286.

Robertson G, Atkinson NS, Ganetzky B (1991) The Drosophila slowpoke gene encodes a putative structural component of a calciumactivated potassium channel. Biophys J 59:196a.

Rudy B (1988) Diversity and ubiquity of K channel. Neuroscience 25:729-749.

Saito M, Wu C-F (1989) Membrane excitability and synaptic activity in cell division-arrested neuroblasts in Drosophila CNS culture. Soc Neurosci Abstr 16:498a.

Saito M, Wu C-F (1990) Whole-cell clamp studies of giant Drosophila neurons differentiated from cell division-arrested neuroblasts. Biophys J 57:130a.

Salkoff L (1983) Drosophila mutants reveal two components of fast transient current. Nature 302:249-251.

Salkoff LB, Tanouye MA (1986) Genetics of ion channels. Physiol Rev 66:301-329.

Salkoff LB, Wyman RJ (1983) Ion currents in Drosophila flight muscles. J Physiol (Lond) 337:687-709.

Salkoff LB, Butler A, Wei A, Scavarda N, Giffen K, Ifune C, Goodman $R$, Mandel $G$ (1987) Genomic organization and deduced amino acid sequence of a putative sodium channel gene in Drosophila. Science 237:744-749. 
Salvaterra PM, Bourrias-Vardiabasis N, Nair T, Hou G, Lieu L (1987) In vitro neuronal differentiation of Drosophila embryo cells. J Neurosci 7:10-22.

Seecof RL, Alleaume N, Teplitz RL, Gerson I (1971) Differentiation of neurons and myocytes in cell cultures made from Drosophila gastrulae. Exp Cell Res 69:161-173.

Singh S, Wu C-F (1989) Complete separation of four $\mathrm{K}^{+}$currents in Drosophila. Neuron 2:1325-1329.

Singh S, Wu C-F (1990) Properties of potassium currents and their role in membrane excitability in Drosophila larval muscle fibers. $\mathrm{J}$ Exp Biol 152:59-76.

Snow P, Patel NH, Harrelson AL, Goodman CS (1987) Neural-specific carbohydrate moiety shared by many surface glycoproteins in Drosophila and grasshopper embryos. J Neurosci 7:4137-4144.

Solc CK, Aldrich RW (1988) Voltage-gated potassium channels in larval CNS neurons of Drosophila. J Neurosci 8:2556-2570.

Solc CK, Zagotta WN, Aldrich RW (1987) Single-channel and genetic analysis reveal two distinct A-type potassium channels in Drosophila. Science 236:1094-1098.

Stafstrom CE, Schwindt PT, Chubb MC, Crill WE (1985) Properties of persistent sodium conductance and calcium conductance of layer $\mathrm{V}$ neurons from cat sensory motor cortex in vitro. J Neurophysiol 53: $153-170$.

Sun Y-A, Wu C-F (1985) Genetic alterations of single channel potassium currents in dissociated central nervous system neurons of Drosophila. J Gen Physiol 86:16a.

Tanouye MA, Ferrus A (1985) Action potentials in normal and Shaker mutant Drosophila. J Neurogenet 2:253-271.
Tanouye MA, Ferrus A, Fujita SC (1981) Abnormal action potentials associated with the Shaker complex locus of Drosophila. Proc Nall Acad Sci USA 78:6548-6552.

Tillotson D (1979) Inactivation of calcium conductance depends on entry of Ca ions in molluscan neurons. Proc Natl Acad Sci USA 76: 1497-1500.

Timpe LC, Jan LY (1987) Gene dosage and complementation analysis of Shaker locus in Drosophila. Annu Rev Neurosci 9:255-276.

Wei A, Salkoff L (1986) Occult Drosophila calcium channels and twinning of calcium and voltage-activated potassium channels. Science 233:780-782.

Wu C-F, Ganetzky B (1988) Genetic and pharmacological analysis of potassium channels in Drosophila. In: Neurotoxin '88. Molecular basis of drug and pesticide action. (Lunt GG, ed), pp 311-323. Amsterdam: Elsevier.

Wu C-F, Haugland FN (1985) Voltage clamp analysis of membrane currents in larval muscle fibers of Drosophila: alteration of potassium currents in Shaker mutants. J Neurosci 5:2626-2640.

Wu C-F, Suzuki N, Poo M-M (1983) Dissociated neurons from normal and mutant Drosophila larval central nervous systems in cell culture. J Neurosci 3:1888-1899.

Wu C-F, Sakai K, Saito M, Hotta Y (1990) Giant Drosophila neurons differentiated from cytokinesis-arrested embryonic neuroblasts. J Neurobiol 21:499-507.

Yawo H, Kojima H, Kuno M (1985) Low-threshold slow-inactivating $\mathrm{Na}^{+}$potentials in the cockroach giant axon. $\mathrm{J}$ Neurophysiol 54:10871100 . 